\title{
A Technical Review of Modeling Techniques for Urban Solar Mobility: Solar to Buildings, Vehicles, and Storage (S2BVS)
}

\author{
Pei Huang ${ }^{1}{ }^{\mathbb{D}}$, Xingxing Zhang ${ }^{1, *} \mathbb{C}$, Benedetta Copertaro ${ }^{1}$, Puneet Kumar Saini ${ }^{1}$, Da Yan ${ }^{2}$, \\ $\mathrm{Yi} \mathrm{Wu}{ }^{2}$ and Xiangjie Chen ${ }^{3}$ \\ 1 Energy Technology, Dalarna University, 79188 Falun, Sweden; phn@du.se (P.H.); bcp@du.se (B.C.); \\ pks@du.se (P.K.S.) \\ 2 School of Architecture, Tsinghua University, Beijing 100084, China; yanda@tsinghua.edu.cn (D.Y.); \\ y-wu17@mails.tsinghua.edu.cn (Y.W.) \\ 3 School of Architecture, Centre for Renewable Energy Systems Technology, Loughborough University, \\ Leicestershire LE11 3TU, UK; X.J.Chen@lboro.ac.uk \\ * Correspondence: xza@du.se; Tel.: +46-(0)-23-77-87-89
}

Received: 24 July 2020; Accepted: 26 August 2020; Published: 28 August 2020

\begin{abstract}
The deployment of solar photovoltaics (PV) and electric vehicles (EVs) is continuously increasing during urban energy transition. With the increasing deployment of energy storage, the development of the energy sharing concept and the associated advanced controls, the conventional solar mobility model (i.e., solar-to-vehicles (S2V), using solar energy in a different location) and context are becoming less compatible and limited for future scenarios. For instance, energy sharing within a building cluster enables buildings to share surplus PV power generation with other buildings of insufficient PV power generation, thereby improving the overall PV power utilization and reducing the grid power dependence. However, such energy sharing techniques are not considered in the conventional solar mobility models, which limits the potential for performance improvements. Therefore, this study conducts a systematic review of solar mobility-related studies as well as the newly developed energy concepts and techniques. Based on the review, this study extends the conventional solar mobility scope from S2V to solar-to-buildings, vehicles and storage (S2BVS). A detailed modeling of each sub-system in the S2BVS model and related advanced controls are presented, and the research gaps that need future investigation for promoting solar mobility are identified. The aim is to provide an up-to-date review of the existing studies related to solar mobility to decision makers, so as to help enhance solar power utilization, reduce buildings' and EVs' dependence and impacts on the power grid, as well as carbon emissions.
\end{abstract}

Keywords: solar mobility; electric vehicles; building cluster; energy storage; energy sharing; advanced control

\section{Introduction}

\subsection{Background}

Building energy use currently accounts for over $40 \%$ of total primary energy consumption in the U.S. and E.U. [1]. The transportation sector also represents a large energy end-user and consumes approximately $25 \%$ of the primary energy worldwide [2]. To meet the large energy needs in both the building sector and transportation sector, renewable energy, which has much lower carbon emissions and relatively lower costs compared with the conventional fossil fuel-based energy, offers a promising solution [3]. In this regard, many countries and associations have established regulations or targets 
to promote the deployment of renewable energy. For instance, the European '20-20-20 targets' aim to achieve a $20 \%$ reduction in $\mathrm{CO}_{2}$ emissions (compared to 1990 levels), $20 \%$ of energy coming from renewables, and a $20 \%$ increase in the energy efficiency by 2020 . The E.U. also sets a target of $32 \%$ of energy generation from renewables by 2030, and a minimum share of at least $14 \%$ of fuel for transport purposes must come from renewable sources by 2030 [1,4]. In different states of the U.S., different renewable energy targets have also been defined. For instance, Connecticut sets a target of $48 \%$ renewable generation share of electricity sales by 2030 , and New Jersey sets a target to increase its renewable portfolio standards target to $50 \%$. Among all the states, California is the most ambitious and sets a goal to achieve $100 \%$ carbon-free power by 2045 [5]. China, as the world's biggest energy consumer, also aims for a 35\% of renewable-based electricity generation by 2030 [6]. In order to achieve these renewable energy targets, two important aspects, the way renewable energy is used and renewable energy self-utilization, should be carefully determined.

\subsubsection{Market Trends of PVs}

The global solar photovoltaics (PV) market is increasing with an approximate exponential trend [7]. In 2018, a total of 102.4 GW PV panels were installed globally, representing a $\%$ year-on-year growth over the $98.5 \mathrm{GW}$ installed in 2017. This led to a total global solar power capacity of over $500 \mathrm{GW}$. The Asia-Pacific region (including China) was leading the global PV market, and it owned more than half $(55 \%)$ of the global solar power generation capacity. In this region, China alone operated nearly $1 / 3$ rd of the world's solar power generation capacities. The European solar pioneers ranked second, but their share slipped to $25 \%$ based on a cumulative PV capacity of $125.8 \mathrm{GW}$. The Americas were the world's third largest solar region in 2018-with a cumulative installed capacity of 78.2 GW and a $15 \%$ stake.

\subsubsection{Market Trends of Electric Vehicles (EV)}

EVs, which are powered by electricity, are considered as a promising solution to roadside air pollution and associated health damage, since they directly cut off pollution from the source. When EVs are charged by renewable energy, such as PV and wind turbines, their operations are totally carbon-free and thus EVs can make substantial contributions to greenhouse gas emissions. To date, a lot of governments have established policies or goals to promote the deployment of EVs. For instance, the Swedish government has set a goal that $100 \%$ of the national energy used in vehicle fleets should be independent of fossil fuel by 2030 [8]. The U.S. Federal government has enacted policies and legislation to promote the U.S. market for EVs, such as improvements in tax credits under current law, and competitive programs to encourage communities to invest in infrastructure supporting these vehicles [9]. The Hong Kong government has made efforts in promoting its practical applications, e.g., tax reductions, a one-for-one replacement scheme, subsidies for EV purchase and EV licenses [10,11]. The Singapore government has shown great interest in adopting EVs [12]. The Energy Market Authority (EMA) and the Land Transport Authority (LTA) of Singapore launched the EV testbed in 2011 to decide on the mass adoption of EV. Following positive results, they approved BlueSG Pte Ltd. [13], a subsidiary of Bolloré Group, to launch an EV car-sharing program by 2017 [4]. The French government set a target of two million EVs in 2020 [14]. The stock of EVs (i.e., the number of EVs on the road) is projected to reach 18.7 million in 2030 [15]. The authors in [16] stipulated the introduction of a Building Plan stating that, with effect from 2020, the deployment of rechargeable electric and hybrid vehicles (HV) should represent $30 \%$ of all vehicle sales by 2020 . Hence, the public acceptance of EVs and their swift global market penetrations because of this are imposing increased impacts on the deployment of PV and smart grids.

\subsubsection{Market Trends of Storage}

As reported by the KPMG (i.e., KPMG International Cooperative), in 2016, the United States had the largest market for energy storage, both by number of projects and installed capacity. In some 
states, innovative energy storage incentive programs have been implemented. A total capacity of $62 \mathrm{MW}$ of energy storage had been installed by 2014, and the country has set the target of a 1325-MW energy storage capacity by 2020. Japan has set an ambitious target to produce half of the world's batteries by 2020 . The country has a subsidy program for $66 \%$ of the cost for homes and business that install lithium-ion batteries. Japan also has a target of 30\% renewables implementation by 2030 . India has a target of $40 \mathrm{GW}$ of renewable energy capacity by 2030. Among the different energy storage types, electricity storage is an economic solution off the grid in solar home systems and in mini-grids where it can also increase the fraction of renewable energy in the system to as high as $100 \%$ [17]. The International Renewable Energy Agency reported a total battery capacity in stationary applications of $11 \mathrm{GW} \cdot \mathrm{h}$ in 2017. The total capacity is expected to reach 100 167 GW.h by 2030 in this case. The large battery storage market is contributed by pairing a battery storage system with the installation of new small-scale solar PV systems. For example, motivated by the financial support for battery storage, nearly $40 \%$ of small-scale solar PV systems in Germany have been installed with battery systems in the past few years. In Australia, although there is no any financial support, nearly 7000 small-scale battery systems were still installed in 2016. The economics of battery storage in such applications are also projected to increase significantly in the future. The growing capacity of energy storage provides great opportunities for renewable energy utilization and promotes solar mobility.

\subsubsection{Building Prosumers Role}

Buildings consume about $40 \%$ of energy worldwide [18], and this percentage is even larger in high-density cities (e.g., over 90\% in Hong Kong) [19]. To reduce the energy usage in the building sector, renewable energy systems, such as PV panels and wind turbines, are widely installed in buildings [20]. By such renewable energy systems integration, buildings are transferring their roles from conventional electricity consumers to electricity prosumers. As defined in [21,22], electricity prosumers are electricity consumers who produce electricity for their own consumption using distributed energy technologies. From the perspective of buildings, this transformation can help cut down grid power usage, thereby reducing the electricity costs as well as reducing carbon emissions if grid power is produced from fossil fuels [23]. From the perspective of the power grid, the reduced demands on the building side can help alleviate the grid stress and thereby promote the power grid's stable and reliable operation [24]. Common types of electricity prosumers are zero energy buildings (ZEBs), which produce the same amount of energy they consume.

To facilitate the application of ZEBs, many governments have established policies and goals. For instance, Directive 2010/31/EU, the Energy Performance of Buildings Directive (EPBD), sets the goal that all new buildings built from the beginning of 2021 must be nearly zero-energy and cost-optimal [25]. The nearly zero energy building strategy 2020 (ZEBRA 2020) was launched by 17 countries in 2014, for the purpose of creating an observatory for net zero energy buildings (NZEBs) based on market studies and various data tools and therefore generates data and evidence for optimization and policy evaluation [26]. The U.S. government sets a target that $50 \%$ of commercial buildings will achieve zero-energy by 2040, and all commercial buildings will achieve zero-energy by 2050 [20]. The California Public Utilities Commission of the USA has set a net zero energy target for all new residential buildings by 2020 and for all new commercial buildings by 2030 [27]. Similar promotion policies and targets can also be observed in China, Korea, Japan and Australia [28]. As reported by Tronchin et al., the built environment represents a suitable intermediate scale of analysis in Multi-Level Perspective planning, collocated among infrastructure and users [29]. Temporal and spatial decoupling of supply and demand is an important element that should be considered for the evolution of built environment, especially when creating sectorial-level planning strategies and policies. They also determined the need for research into developing innovation pathways for the co-evolution of the built environment and infrastructure. In such a context, the analysis of complementarities is particularly powerful and should receive more attention. Solar mobility development, which seeks complementarities in multiple systems (i.e., buildings, EVs, PVs and energy storage), is in line with this context. 


\subsection{Defining the Concept of Solar Mobility}

As proposed by CEA-INES (namely the French National Institute for Solar Energy) [30], the concept of solar mobility seeks a synergy between the following three systems: EVs, PV systems and the electricity network. The basic idea is to combine a standard grid-connected PV system with standard EVs, also connected to the grid [31]. In order to ensure the solar charging of the vehicles and minimize the grid impact, a local Energy Management System decides on the energy flows. This process is called solar-to-vehicles (S2V) in some studies [32], representing charging EVs directly using electricity from PVs. Vehicles can be charged at home using residential charging stations or at public charging stations in private business or public car parks. They consider such a process reasonable since the average car is parked $95 \%$ of the time and charging can take a long time based on current usage models. In their proposed concept, the electricity produced by the residential PV panels is firstly used to supply the home electrical equipment (e.g., household appliances, multimedia devices, etc.), and then to charge the EV battery, as shown in Figure 1. If there is any surplus generation, such an amount is fed into the power grid. The smart grid will collect data on the grid loads and power needs and redistribute the surplus generation to meet these loads/needs. In such a context, buildings, equipped with PV systems and energy storage systems, are becoming energy production sites where EVs can be charged. This convergence between buildings and transport will enable EV batteries to be used as a means of storage and supply of low-carbon electricity to meet fluctuations in production and consumption. Note that the EV battery is also allowed to discharge electricity back to the building/power grid in such a model. This is advantageous for grid management and especially for peak smoothing. This concept has been extensively studied from a technological viewpoint in [33-38].

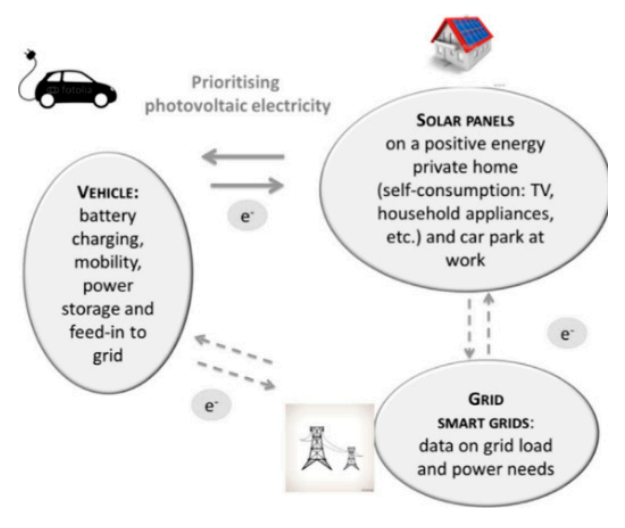

Figure 1. Concept of solar mobility with self-consumption [31].

\subsection{Values, Problems and Challenges to the Solar Mobility}

Values: With the increasing deployment of PVs, EVs and energy storage systems, it is important to smartly integrate them to maximize the energy efficiency and cost benefits and, meanwhile, minimize the impact on the power grid. Under such a context, solar mobility can help improve three values: autonomy, sustainability, and affordability. Specifically, autonomy indicates reducing the dependence and impacts on the public power grid. Ideally, within a building community/microgrid, by acting as an electricity prosumer and considering the EV demand, buildings can be largely covered by their own PV system. Sustainability indicates increasing the self-consumption of locally produced PV power, and thus the need for power from the public grid, which largely depends on fossil energy in many countries. Affordability indicates increasing the economic benefits of the whole system.

Problems: Although the importance of PVs, EVs, and energy storage has been well recognized globally, how to integrate and manage them in a holistic way, simultaneously taking into consideration building loads and occupants' living requirements, needs to be addressed. Problems such as large power penetration in the power grid, low energy efficiency and low economic performance urgently need to be solved. Moreover, with the development of the energy sharing concept and associated 
advanced controls, the conventional solar mobility concept and context are becoming less compatible and limited. For instance, energy sharing within a building cluster enables buildings to share their surplus generation with other buildings (including their EV demands) with insufficient supply, thereby helping improve the overall renewable energy utilization and reducing grid power dependence. However, such energy sharing networks, including the system architecture and associated advanced controls, are not considered in the conventional solar mobility models. This will limit the potential for performance improvements that can be otherwise be articulated and demonstrated by the newly developed concepts and methods. Another example is the lack of energy storage integration in the existing solar mobility model (note that, in this study, EVs are considered to have a separate role from energy storage).

Challenges: Intermittency is one of the major shortfalls of solar power, which has a direct influence on the voltage stability and the overall power system security, while, for EVs, their charging loads are difficult to predict as they are highly affected by driving patterns and driving distances. Both PV power production and EV power demand are highly uncertain. For instance, an EV can be used for commuting purposes during the day where access to charging facilities is not available. This means that charging could only happen in an EV owner's premises during the nighttime when no electricity can be generated by PV. Such time mismatches will limit the deployment of solar energy in the mobility sector. Thus, it is challenging to bridge the temporal and spatial supply-demand mismatch to facilitate solar mobility. When buildings and energy storage are integrated into the solar mobility context, another challenge is the proper management of different types of systems with various response characteristics and operating constraints. This review paper will aim to propose some useful solutions from existing studies to address these challenges.

\subsection{Aim and Contributions of This Review}

This study conducts a technical review of solar mobility-related studies as well as newly developed energy concepts and techniques. By reviewing the existing studies [39-41], this study extends the conventional solar mobility model from S2V to solar-to-buildings, vehicles and storage (S2BVS). In the extended context, solar mobility involves solar energy flow and exchange through buildings, vehicles and storage and the renewable energy sharing network. The electricity generated by PV panels is applied to provide electricity to buildings and charge batteries/thermal energy storage (e.g., by heat pump (HP)), while EVs can be charged at residential charging stations or at public charging stations in private business or public car parks. The associated S2BVS system architecture and models are proposed, and the associated advanced controls in the existing literature are reviewed. The aim is to help improve the solar mobility concept by introducing up-to-date S2BVS models, to enhance renewable energy utilization, reduce the dependence and impacts of buildings and EVs on the power grid, and reduce the carbon emissions in response to a future scenario with increased PV capacity, EV numbers and storage capacity. The major contributions of this review are summarized as follows:

- Assess values, problems and challenges of solar power deployment to promote solar mobility.

- Extend the existing solar-to-vehicles (S2V) concept to solar-to-buildings, vehicles and storage (S2BVS) with the integration of renewable energy systems, buildings, energy storage systems, EVs and, more importantly, the renewable energy sharing network.

- Identify the research gaps that need future investigation to promote solar power utilization and solar mobility.

\section{Overview of the Existing Studies on Solar Mobility}

Extensive efforts have been devoted to promoting solar mobility, and many papers have been published regarding this topic. Figure 2 defines the extended scope of solar mobility (compared with Figure 1) and highlights the location of reviews for each sub-system. Table 1 summarizes the main existing studies with such a scope. 
Table 1. Summary of the existing studies on solar mobility.

\begin{tabular}{|c|c|c|c|c|c|c|c|c|c|}
\hline \multirow[b]{2}{*}{ Authors } & \multirow[b]{2}{*}{ Region } & \multicolumn{5}{|c|}{ System } & \multirow[b]{2}{*}{ Modeling Tools } & \multirow[b]{2}{*}{ Main Work Done } & \multirow[b]{2}{*}{ Special Points } \\
\hline & & Building & PV & Storage & EVs & $\begin{array}{c}\text { Other } \\
\text { Techniques }\end{array}$ & & & \\
\hline $\begin{array}{l}\text { Berthold et al. } \\
\text { (2011) [42] }\end{array}$ & France & Y & Y & $\mathrm{N}$ & Y & $\begin{array}{l}\text { Wind } \\
\text { energy }\end{array}$ & - & $\begin{array}{l}\text { Developed a general control strategy which } \\
\text { aims at minimizing the building's total energy } \\
\text { costs by optimizing the charging/discharging } \\
\text { of PHEVs' batteries. The considered systems } \\
\text { include the power grid, local production from } \\
\text { renewables, and vehicles. Using the EV } \\
\text { battery to power home appliances is allowed. }\end{array}$ & $\begin{array}{l}\text { Unlike conventional } \\
\text { home-to-vehicle }(\mathrm{H} 2 \mathrm{~V}) \text {, } \\
\text { this study also enables } \\
\text { vehicle-to-home (V2H) for } \\
\text { demand response control. }\end{array}$ \\
\hline $\begin{array}{c}\text { Querini et al. } \\
\text { (2012) [43] }\end{array}$ & $\begin{array}{c}\text { Germany, } \\
\text { Denmark, } \\
\text { Sweden, Spain, } \\
\text { France, UK, Italy. }\end{array}$ & $\mathrm{N}$ & Y & $\mathrm{N}$ & Y & $\begin{array}{l}\text { Wind } \\
\text { energy }\end{array}$ & Gabi4 & $\begin{array}{l}\text { 1. Studied the life cycle of greenhouse gas } \\
\text { (GHG) emissions linked with EVs using PV } \\
\text { and wind electricity in different regions of } \\
\text { European countries. } \\
\text { 2. Analyzed the life cycle of GHG emissions } \\
\text { using wind energy, solar energy, and } \\
\text { conventional fossil fuel. }\end{array}$ & $\begin{array}{l}\text { When using PV electricity, } \\
\text { GHG emissions are always } \\
\text { lower than conventional } \\
\text { thermal vehicles }\end{array}$ \\
\hline $\begin{array}{l}\text { Zhang et al. } \\
\text { (2012) [35] }\end{array}$ & Kansai, Japan & $\mathrm{N}$ & Y & $\mathrm{N}$ & Y & $\begin{array}{l}\text { Heat pump } \\
\quad(\mathrm{HP})\end{array}$ & $\begin{array}{l}\text { Visual Studio } \\
\text { C\#.net } 2008\end{array}$ & $\begin{array}{l}\text { 1. Developed an hour-by-hour simulation } \\
\text { model to derive a real-time supply-demand } \\
\text { balance. 2. Evaluated the impacts of } \\
\text { integrating PV power into future electricity } \\
\text { systems with EVs and HPs under smart } \\
\text { control strategies in Kansai. } 3 \text {. Analyzed a set } \\
\text { of scenarios with different penetrations of PV, } \\
\text { EV and HP. }\end{array}$ & $\begin{array}{l}\text { The EVs are considered as } \\
\text { virtual batteries, similar to } \\
\text { electricity storage systems, } \\
\text { which can not only be } \\
\text { charged by grid power } \\
\text { (G2V), but can also discharge } \\
\text { electricity to the power } \\
\text { grid (V2G). }\end{array}$ \\
\hline $\begin{array}{l}\text { Dallinger et al. } \\
\text { (2013) [44] }\end{array}$ & $\begin{array}{l}\text { Germany and } \\
\text { U.S. (California) }\end{array}$ & $\mathrm{N}$ & Y & $\mathrm{N}$ & Y & $\mathrm{N}$ & PowerACE & $\begin{array}{l}\text { 1. Developed a method to characterize the } \\
\text { fluctuating electricity generation of renewable } \\
\text { energy sources and compare the difference } \\
\text { between California and Germany. } \\
\text { 2. Analyzed the potential contribution of } \\
\text { grid-connected vehicles to balance the } \\
\text { generation from renewable energy sources for } \\
\text { a } 2030 \text { scenario in California and Germany } \\
\text { based on the developed method. }\end{array}$ & $\begin{array}{l}\text { 1. Correlation between } \\
\text { renewable energy system } \\
\text { generation and the load } \\
\text { curve affecting the } \\
\text { integration of RES. 2. EVs } \\
\text { play an important role in } \\
\text { reducing residual load } \\
\text { fluctuation if smart charging } \\
\text { is used. }\end{array}$ \\
\hline
\end{tabular}


Table 1. Cont.

\begin{tabular}{|c|c|c|c|c|c|c|c|c|c|}
\hline \multirow[b]{2}{*}{ Authors } & \multirow[b]{2}{*}{ Region } & \multicolumn{5}{|c|}{ System } & \multirow[b]{2}{*}{ Modeling Tools } & \multirow[b]{2}{*}{ Main Work Done } & \multirow[b]{2}{*}{ Special Points } \\
\hline & & Building & PV & Storage & EVs & $\begin{array}{c}\text { Other } \\
\text { Techniques }\end{array}$ & & & \\
\hline $\begin{array}{l}\text { Su et al. } \\
\text { (2014) [45] }\end{array}$ & Illinois, U.S. & $\mathrm{N}$ & $\mathrm{Y}$ & Y & Y & $\begin{array}{l}\text { Wind } \\
\text { energy }\end{array}$ & $\begin{array}{l}\text { CPLEX+ Matlab+ } \\
\text { OpenDSS }\end{array}$ & $\begin{array}{l}\text { 1. Formulated a stochastic problem for } \\
\text { microgrid energy scheduling, which aims at } \\
\text { minimizing the expected operational cost of } \\
\text { the microgrid and power losses by optimally } \\
\text { dispatching the EV charging load and } \\
\text { scheduling distributed generators and } \\
\text { distributed energy storage devices. } \\
\text { 2. Investigated the impact of EVs on } \\
\text { microgrid energy scheduling under various } \\
\text { charging schemes. }\end{array}$ & $\begin{array}{l}\text { Combined scheduling of EV } \\
\text { charging loads and energy } \\
\text { storage systems. }\end{array}$ \\
\hline $\begin{array}{l}\text { Chaouachi et al. } \\
\text { (2016) [46] }\end{array}$ & Italy & $\mathrm{N}$ & $\mathrm{Y}$ & $\mathrm{N}$ & Y & $\mathrm{N}$ & $\begin{array}{l}\text { Matpower open } \\
\text { source package }\end{array}$ & $\begin{array}{l}\text { 1. Proposed a conceptual smart grid } \\
\text { framework and assessment methodology, to } \\
\text { enable decentralized operational synergy } \\
\text { between intermittent PV generation and EVs, } \\
\text { based on coordinated EV charging. } 2 \text {. Tested } \\
\text { the proposed methodology with a real } \\
\text { distribution system, where different PV and } \\
\text { EV penetration scenarios are assessed against } \\
\text { charging behavior variants. }\end{array}$ & $\begin{array}{l}\text { Impacts of coordinated } \\
\text { charging on PV penetration } \\
\text { and carbon emission reduction }\end{array}$ \\
\hline $\begin{array}{l}\text { Islam and } \\
\text { Mithulananthan } \\
\text { (2017) [47] }\end{array}$ & Australia & $\mathrm{N}$ & $\mathrm{Y}$ & $\mathrm{N}$ & Y & $\mathrm{N}$ & Matlab & $\begin{array}{l}\text { 1. Developed a non-iterative PV output } \\
\text { model that does not require additional } \\
\text { measurements or meteorological data, } \\
\text { which saves money and time. 2. Developed a } \\
\text { combined, Stage of Charge (SOC)-based, } \\
\text { fair charging strategy which simultaneously } \\
\text { reduces the runtime by lowering the number } \\
\text { of variables involved and increases the } \\
\text { charging fairness. The reduced runtime } \\
\text { makes it suitable for more frequent control of } \\
\text { charging of a large EV population. }\end{array}$ & $\begin{array}{l}\text { Consider grid-side } \\
\text { parameters, such as voltage } \\
\text { topology, structure, etc. } \\
\text { The PV output model and } \\
\text { charging strategy together } \\
\text { lessen the probability of } \\
\text { voltage limit violations and } \\
\text { enhance the PV harvest. }\end{array}$ \\
\hline
\end{tabular}


Table 1. Cont

\begin{tabular}{|c|c|c|c|c|c|c|c|c|c|}
\hline \multirow[b]{2}{*}{ Authors } & \multirow[b]{2}{*}{ Region } & \multicolumn{5}{|c|}{ System } & \multirow[b]{2}{*}{ Modeling Tools } & \multirow[b]{2}{*}{ Main Work Done } & \multirow[b]{2}{*}{ Special Points } \\
\hline & & Building & PV & Storage & EVs & $\begin{array}{c}\text { Other } \\
\text { Techniques }\end{array}$ & & & \\
\hline $\begin{array}{l}\text { Sun et al. } \\
(2018)[48]\end{array}$ & Glasgow, UK & Y & $\mathrm{Y}$ & Y & $\mathrm{Y}$ & $\mathrm{N}$ & $\begin{array}{c}\text { Matlab (GA } \\
\text { optimization tool) }\end{array}$ & $\begin{array}{l}\text { 1. Developed a model for minimizing the } \\
\text { energy cost of a residential household with an } \\
\text { EV, a shared energy storage system (ESS), } \\
\text { and other residential loads, where the EV's } \\
\text { usage patterns are described by probability } \\
\text { levels. } 2 \text {. Conducted a practical survey of EV } \\
\text { daily usage including driving purposes and } \\
\text { usage at different time periods. } 3 \text {. Investigate } \\
\text { the total cost saving through case studies for } \\
\text { various scenarios under fixed and time of use } \\
\text { (TOU) tariffs. }\end{array}$ & $\begin{array}{l}\text { The optimization } \\
\text { results based on this model } \\
\text { can be used to determine } \\
\text { whether V2G is beneficial for } \\
\text { EV owners under the } \\
\text { optimal charging and } \\
\text { discharging strategy. }\end{array}$ \\
\hline $\begin{array}{l}\text { Taşcıkaraoğlu } \\
\text { (2018) [39] }\end{array}$ & Austin, TX, USA & Y & $\mathrm{Y}$ & Y & $\mathrm{N}$ & $\begin{array}{c}\text { Energy } \\
\text { sharing } \\
\text { network }\end{array}$ & $\begin{array}{l}\text { General Algebraic } \\
\text { Modeling System } \\
\text { (GAMS) with } \\
\text { solver CPLEX }\end{array}$ & $\begin{array}{l}\text { 1. Developed the concept of energy } \\
\text { sharing-enabled neighborhood area networks, } \\
\text { which are composed of a shared energy } \\
\text { storage system and multiple consumer } \\
\text { premises. 2. Developed a novel energy } \\
\text { management strategy based on the } \\
\text { implementation and scheduling the use of } \\
\text { this shared energy storage system (ESS) with } \\
\text { the objective of exploiting the ESS unit in the } \\
\text { context of an energy credit-based demand } \\
\text { response program. }\end{array}$ & $\begin{array}{l}\text { Energy sharing-enabled } \\
\text { neighborhood area networks } \\
\text { (NANs) for cluster-level } \\
\text { performance improvements. } \\
\text { Such energy sharing can } \\
\text { reduce the energy costs and } \\
\text { peak demand significantly. }\end{array}$ \\
\hline $\begin{array}{l}\text { Huang et al. } \\
\text { (2019) [49] }\end{array}$ & Yuxi, China & $\mathrm{Y}$ & $\mathrm{Y}$ & $\mathrm{N}$ & Y & $\mathrm{N}$ & $\begin{array}{l}\text { HOMER (for } \\
\text { demand/supply } \\
\text { calculation) Matlab } \\
\text { (for control) }\end{array}$ & $\begin{array}{l}\text { 1. Proposed a retired EV battery (REVB) } \\
\text { model based on the mathematical model of } \\
\text { capacity fade of Li-ion battery cells to } \\
\text { simulate REVB's capacity loss. } 2 \text {. Developed } \\
\text { a power management system to mitigate the } \\
\text { degradation of REVB and protect other } \\
\text { system components. 3. Constructed a } \\
\text { tri-objective optimization model considering } \\
\text { reliability, energy waste and cost. }\end{array}$ & $\begin{array}{l}\text { Use retired EV batteries for } \\
\text { energy storage in buildings. }\end{array}$ \\
\hline $\begin{array}{l}\text { Barone et al. } \\
\text { (2019) [50] }\end{array}$ & Naples, Italy & $\mathrm{Y}$ & $\mathrm{Y}$ & $\mathrm{N}$ & Y & $\mathrm{N}$ & Matlab & $\begin{array}{l}\text { Proposed a novel energy management system } \\
\text { for buildings connected in a microgrid, } \\
\text { by considering EVs as active storage } \\
\text { components of such an energy scheme. }\end{array}$ & $\begin{array}{l}\text { Such B2V2B (i.e., Building to } \\
\text { vehicle to building) } \\
\text { integration enables } \\
\text { renewable sharing among } \\
\text { different buildings. }\end{array}$ \\
\hline
\end{tabular}




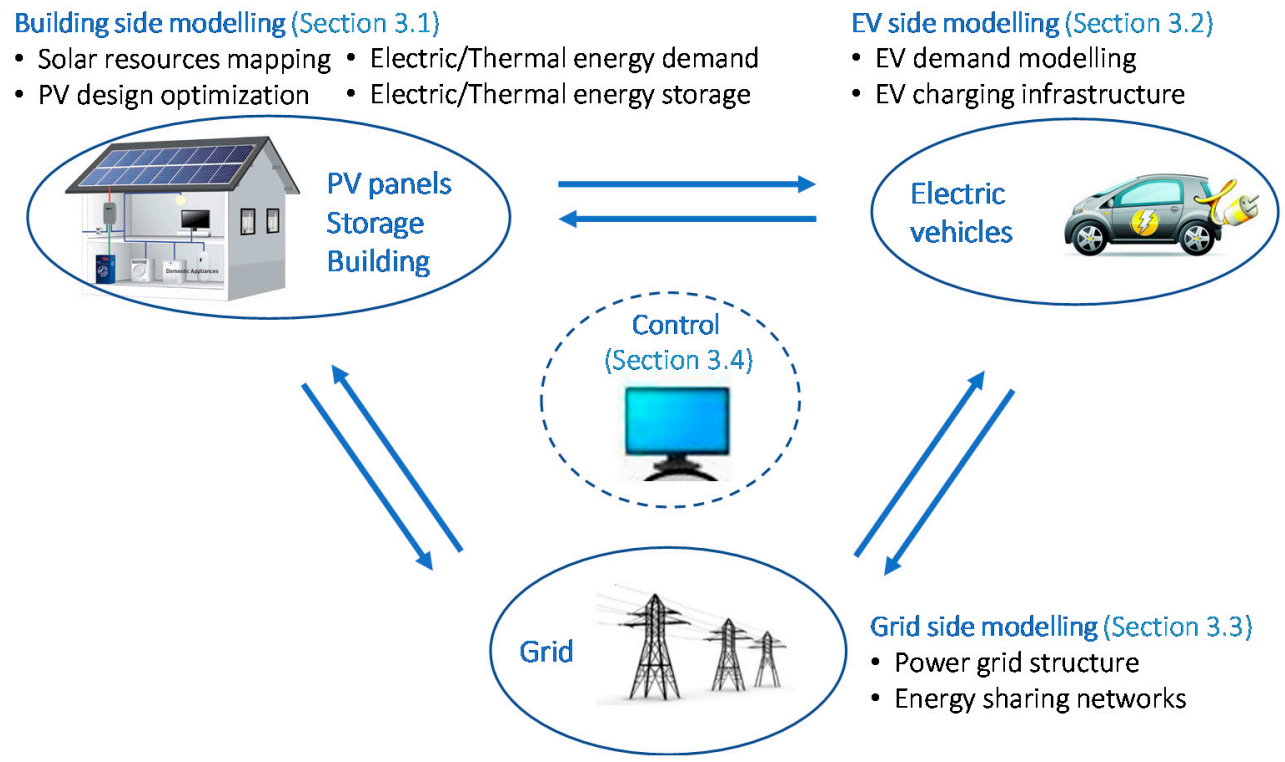

Figure 2. Scope of solar mobility and the major sub-systems.

In the extended solar mobility scope, the energy prosumers are equipped with their own renewable energy systems, electrical storage, EVs and other electrical appliances. The buildings are connected in a renewable energy sharing microgrid, in which the surplus renewable production can be delivered from one building to another. Such an energy sharing network provides a platform for the buildings in a microgrid to share their surplus renewable energy generation with other buildings, thus helping enhance the overall cluster-level performances. The energy sharing microgrid is also connected to the power grid, in case there is surplus/insufficient cluster-level renewable generations and electricity exchanges with the power grid are needed. The power exchange of the building cluster with the power grid is metered by advanced metering facilities.

\section{1. $P V$ and EV Interaction via the Public Grid}

Making use of the charging/discharging capability of EV battery, the EVs can be used as flexible electricity storage in the power grid and interact directly with the power grid. For instance, Zhang et al., investigated the energy and environmental impacts of integrating PV power into electricity systems in Kansai, Japan, under various scenarios with different EV penetrations and heat pump capacities [35]. It was found that EVs and heat pumps were helpful for keeping more PV power in the smart electricity systems. In their study, the EVs were considered as virtual batteries, similar to electricity storage systems, which can not only be charged by grid power (G2V), but can also discharge electricity to the power grid (V2G). Sun et al., investigated the economy viability of discharging EV power back to the grid, which is called vehicle-to-grid (V2G) [48]. They developed a model for the minimization of the energy cost of a residential household with residential loads, an ESS, and an EV with its usage patterns described by probability levels. Using the developed model, they studied the total cost saving for various scenarios under fixed and time of use (TOU) tariffs. Their study results reveal that certain threshold levels of feed-in tariffs are expected to allow users benefit from V2G technology. Noussan and Neirotti compared three archetypal charging profiles (i.e., home, public and work) evaluated on 10 European countries over four years, to investigate the effects of national electricity mixes and of the type of charging location on the average emission factor of the electricity supplied to electric vehicles [51]. Their study results show that the variability related to charging profiles is generally limited (with an average variation range of $6 \%$ ) in all the selected countries, while in several countries the variability in different years is much larger (with an average range of $18 \%$ ). 


\section{2. $P V$ and EV Interaction via the Buildings}

Besides being used for electricity storage in the power grid, the EVs can also be used as flexible electricity storage systems in buildings. For instance, Berthold et al., developed a control strategy, which aims at minimizing the building's total energy costs by optimizing the charging/discharging of the batteries of plug-in hybrid electric vehicles (PHEVs) [42]. The considered systems include the power grid, local production from renewable energy systems, and vehicles. Unlike the conventional controls which only enable home to EV (H2E) power transmission, this study also enables EV to home (V2H) power transmission, which extends the utilization of EVs in terms of the building demand response. In order to maximize the value of EV batteries, Huang et al., proposed a retired EV battery (REVB) model based on the model of capacity fading of lithium battery cells [49]. Using the developed REVB model, a power management strategy (PMS), which considers multiple objectives including minimizing the loss of power supply, system cost and potential energy waste, was developed to regulate the energy flow to protect the REVB and other system components. A multi-objective evolutionary algorithm, NSGA-II, was used to generate the Pareto set of the optimal solution. The application of the developed method in a residential building indicates that a PV-hydrogen-REVB hybrid energy system is a promising way to exploit REVBs' residual capacities. Similarly, Barone et al., proposed the concept 'Building-to-Vehicle-to-Building' (B2V2B), which enables the bidirectional electricity exchange of EV batteries with buildings [50]. They also developed a novel energy management system for buildings connected in a microgrid, by considering EVs as active components of such an energy scheme. Renewable energy sources (i.e., PV), energy storage systems and bidirectional electricity exchange with the buildings and the grid were taken into account. A highlight of their proposed system is that PV power sharing is enabled among different buildings by applying bidirectional EV charging/discharging, as shown in Figure 3. Such energy sharing can significantly improve PV power utilization, and thus bring economic and environmental benefits.

(a) Unidirectional B2V system operation

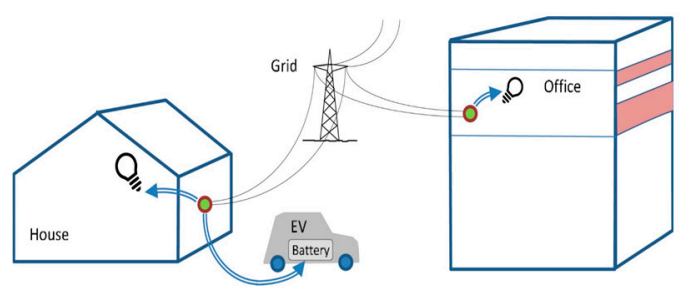

(c) Bidirectional B2V2B system operation, based on swappable batteries

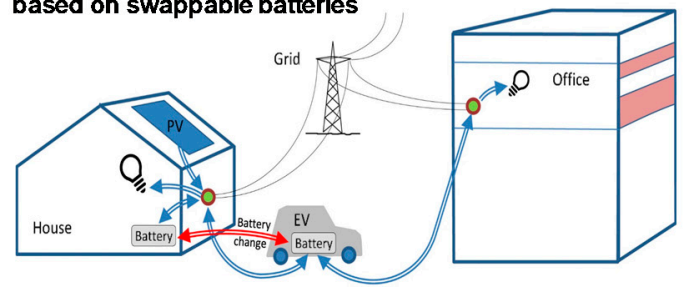

(b) Bidirectional B2V2B system operation

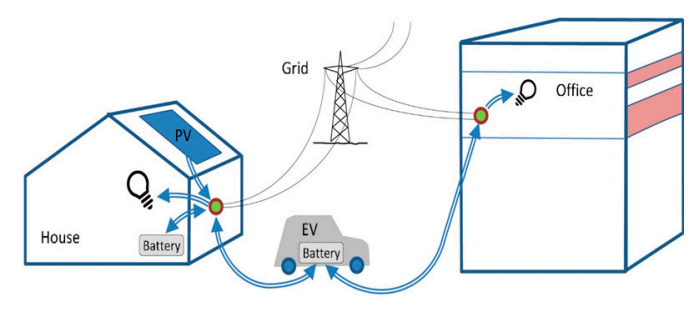

(d) Bidirectional B2V2B system operation, no dedicated battery

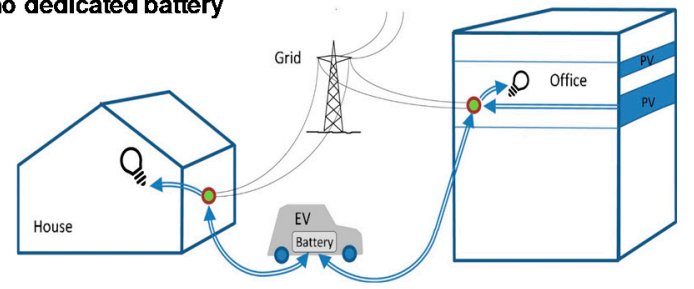

Figure 3. Four different methods of building-electric vehicle (EV)-solar photovoltaics (PV)-grid integration [50].

In Figure 3, Case 1 represents the conventional unidirectional Building-to-Vehicle (B2V) system operation. Here, the plug-in EV is linked with the power grid by acting as a power load. The EV is charged through a home charger and no renewable energy systems and batteries are installed on site. Case 2 represents a novel concept of bidirectional Building-to-Vehicle-to-Building (B2V2B) system operation. The plug-in EV is linked with the power grid acting as a power load as well as a source for the house building, and as a source for the office space. A renewable energy system, consisting of 
PV panels, is installed on site on the tilted roof of the house building. The house is also equipped with a stationary battery (HSB), which can also feed the EV battery (in case of available stored energy, otherwise the EV battery is conventionally supplied by the grid). An additional novelty is represented here by the transfer to the office, through an EV battery, of the electricity potentially produced by the house's PV panels. The EV battery can also be charged at the office, if necessary. Case 3 also represents a novel concept of bidirectional Building-to-Vehicle-to-Building (B2V2B) system operation, based on swappable batteries. The system operation follows that of Case 2. The difference with Case 2 lies in the batteries; specifically, in Case 3 the house is equipped with a battery identical to the EV one and a quick swap of batteries is allowed between the EV and the house. The swapping option prevents the need for energy transfer from the HSB to the EV battery (when EV battery charge is required), and thus related losses. Case 4 represents a different novel concept of bidirectional V2B system operation. The main difference with the previous Cases 1 and 2 is related to the site of the PV panels, which are installed on the façade of the office space, where no dedicated battery (i.e., HSB) is considered (solar energy is stored directly into the EV battery). The plug-in EV communicates with the power grid, acting, in this case, as a power load as well as a source for the office space, and as a source only for the house building. In Case 4, the novelty is represented by the possible transfer to the house, through an EV battery, of electricity produced by the office's PV panels. The EV can be charged both at the house and office buildings.

\subsection{PV and EV Interaction via the Energy Sharing Network Considering Buildings and Energy Storage}

In addition to making use of the flexibility charging/discharging capability of EVs to enable energy sharing, a more direct way (i.e., micro power grid) can also be used for a large amount of energy sharing. For instance, Taşcıkaraoğlu developed a system structure for a shared energy storage system (ESS) in a neighborhood community, as shown in Figure 4 [39]. In their study, each building is equipped with a top PV-based distributed generation system and is connected to a shared ESS. The shared ESS, the transformer and all the households are connected to a common point, which is named the point of common coupling (PCC). Bi-directional power flow is enabled between PCC and the power grid via a neighborhood transfer, between PCC and the shared ESS, and also between buildings and PCC. Such system configuration makes three types of power exchange available, i.e., internal local power exchanges among the neighborhood buildings, power exchanges between the neighborhood buildings and the grid, and power exchanges between the shared ESS and grid/neighborhood buildings. In other words, the power consumed by a building can be produced by its PV system, be produced locally by the PV system of other buildings and/or be drawn from the power grid/shared ESS. The EVs' charging load is considered as a normal electricity load in this study. By sharing the ESS, the buildings can deliver their surplus renewable energy to other buildings with insufficient supply, thus increasing the overall renewable self-utilization rates and, meanwhile, reducing the interactions with the power grid. Their study results show that shared storage can help decrease the peak electricity demand of a building cluster by as much as $30 \%$ and, meanwhile, reduce the electricity costs of the building cluster by over $10 \%$. However, the investment in a shared ESS with a large capacity will be much higher than distributed ESS with small capacities. In addition, the energy losses may be large due to the long transmission distance from the buildings to the shared ESS.

Zhang et al., also developed a novel structure for promoting solar mobility in residential buildings, as shown in Figure 5 [40]. In their study, each residential building has a microgrid, which connects the electricity production facilities (e.g., PV panels) and electricity consumption devices (e.g., lighting, washing machine, EVs, etc.). The EVs are used for flexible electricity storage which can be charged by the PV system/grid electricity in periods with sufficient supply or discharge power to buildings/the power grid in periods with insufficient supply. An aggregator is utilized to connect multiple microgrids, which coordinates the energy sharing among different microgrids as well as their interactions with the power grid. Based on the developed system structure, they developed a two-stage control method to control the EV charging/discharging rates as well as the energy trades within the multiple 
microgrids and with the power grid. Compared with the concept proposed by Barone et al. [50], which uses EV batteries with limited capacity as the medium for energy sharing among different buildings, Zhang et al.'s developed structure is much more flexible and enables larger amount of energy sharing. However, the stochastic charging behavior of EVs, the integration of thermal energy storage systems and dynamic electricity prices are not considered in their study. Moreover, the initial costs for constructing such microgrid would be high, which may create a hurdle for this method's large-scale application.

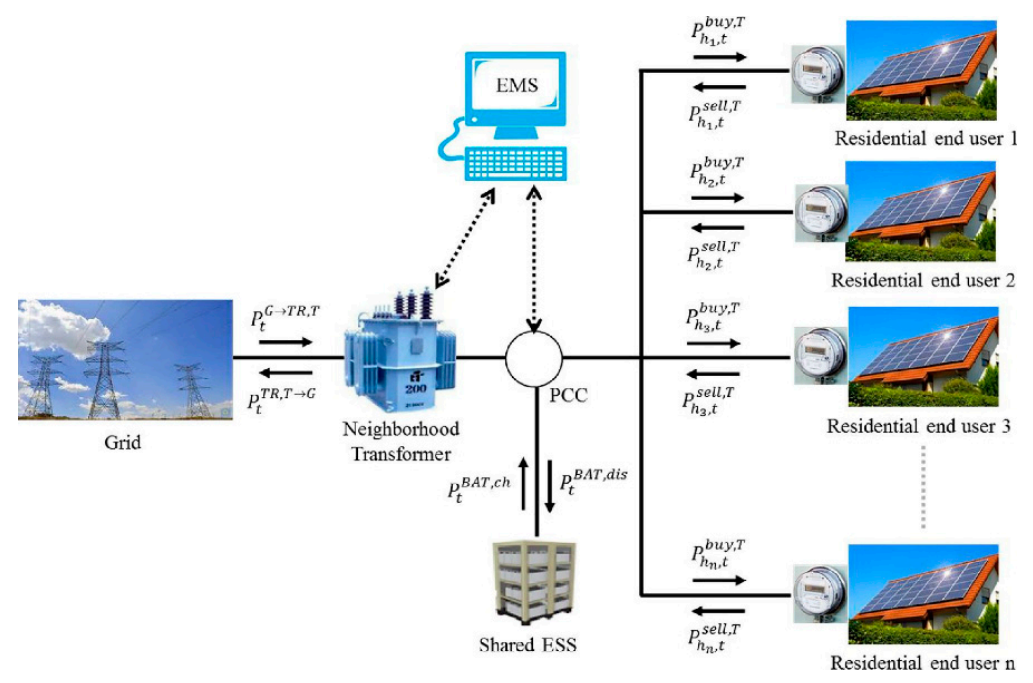

Figure 4. Schemes of the shared energy storage system (ESS) unit serving a neighborhood with multiple households [39].

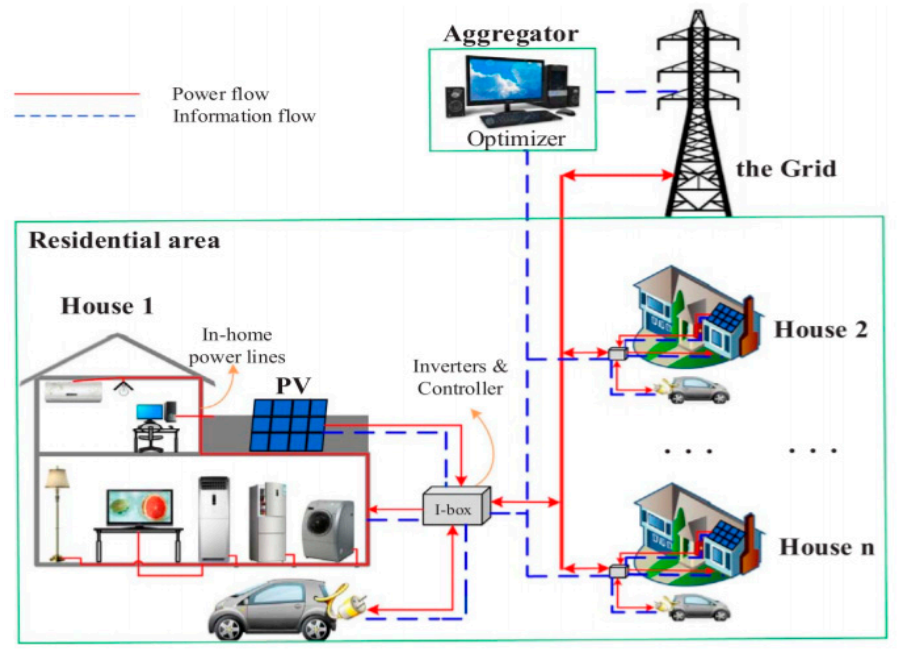

Figure 5. The structure of multiple residential microgrids [40].

Similarly, Huang et al., applied advanced energy concepts for retrofitting a residential building cluster in Sweden [41]. The studied system includes PV panels (installed in individual buildings), centralized thermal energy storage, a heat pump, and EVs. A direct current (DC) microgrid-based energy sharing network, which is developed by Ferroamp, is constructed in the building cluster. The excessive PV production can be stored in the form of heat energy in the thermal storage by powering the heat pump to work. Their study results show that by enabling renewable energy sharing and integrating energy storage and EVs, the PV power self-utilization can be as high as $77 \%$ in the baseline case.

To summarize, existing studies have developed three approaches for deploying PV power in the EVs, i.e., via public power grid, via buildings, and via energy sharing networks considering buildings 
and energy storage. Among these three approaches, the third approach is superior to the other two approaches, as the energy sharing network makes the EV charging more flexible (i.e., from different PV power sources) and efficient (i.e., with enhanced PV power local usage), and allows the integration of two other important players (i.e., buildings and energy storage) in the energy systems. Such an extended scope of solar mobility, with PVs, EVs, energy storage, buildings (i.e., S2BVS), and energy sharing networks, is a future development trend.

\section{Modeling of Sub-Systems}

This section reviews the modeling techniques in the essential components related to solar mobility, including building-side modeling, EV-side modeling, grid modeling and advanced control. Design and control optimization are two main means to help improve the deployment and utilization of solar energy. This section will review these two aspects.

\subsection{Building Side Modeling}

\subsubsection{Solar Resource Mapping}

There are several commercial databases available for solar resource mapping such as Meteonorm [52] and global solar Atlas [53]. These tools make use of data inputs from geostationary satellites and meteorological models such as air temperature models and clear-sky models to predict the incident energy on earth surface at a defined spatial-temporal resolution. Zhang et al., carried out a critical review and compared various models which are used to estimate solar irradiation on basis of time scale and estimation methods [54]. Basharat et al., compared 78 different models used for global solar irradiation estimation [55]. They proposed a systematic classification of these models based on the input parameters which can be used to do a similar analysis. The solar resource data obtained from various tools are often detached from surface topography and the spatial distribution of the building stocks. However, while estimating the solar resource potential in an urban context, it is important to consider the effect of various objects such as neighboring buildings on total incident surface irradiation.

Most of the commercially available databases do not consider the effect of urban climate on the solar resources. The atmospheric thermodynamics in an urban climate are affected by several factors such as topography, shading objects, vegetation, urban infrastructure and the heat island effect [56]. The simulation of an energy system based on a weather database, which does not consider these factors, can result in mismatches between the simulated and real energy system performances. To address such issues, researchers have proposed to couple the geographic information system (GIS) tool and meteorological databases to assess the solar potential in an existing urban context. For instance, Quan et al., proposed a GIS-based energy modeling system for the urban energy context which integrates building energy modeling and solar resource modeling using a three-dimensional urban environmental engine [57]. Bergamasco et al., proposed and applied a hierarchical procedure which makes use of GIS data, available solar radiation maps and statistical data on energy consumption, to determine the PV energy potential for an Italian climatic location [58]. With the development in the availability of high-quality light detection and ranging (LIDAR) data, there is significant interest from various stakeholders to integrate urban-scale 3D models and LIDAR data for high-accuracy energy potential estimations on the urban scale [59]. Jochem et al. [60] proposed a methodology for solar potential estimation in urban climates using airborne LIDAR data and 3D information from the point cloud.

\subsubsection{PV Design Optimization}

The installation of PV arrays (e.g., their position on building facades and their tilt angles) has significant impacts on PV power production. Existing studies have investigated the impacts of these factors and developed proper methods to optimize them. For instance, Abdul-Wahab et al., employed a Hybrid Optimization Model for Electric Renewables (HOMER) to find the best PV system among 15 
available alternatives and the best location for installing PV arrays for Oman's conditions by analyzing and comparing their costs and the carbon emission reductions [61]. Ning et al., developed a genetic algorithm-based optimization method to design the position, tilt angles and azimuth of PV panels, with factors such as shapes and orientations of building exteriors and the surrounding obstacles considered [62]. Their method can effectively improve the PV system power output by $36.1 \%$ and reduce the capital investment per unit power output by $4.5 \%$, meanwhile significantly reducing the human labor. Similarly, Magnor and Sauer also developed a genetic algorithm-based optimization method to optimize PV system installation, including the tilt angle and azimuth angle of the PV generator under various boundary conditions. Ullah et al., developed a method to optimize the PV tilt angle under different scenarios (fixed, seasonal, monthly, daily) for Lahore and some of the other major cities in Pakistan [63]. They also proposed a model to estimate the upper/lower bounds of soiling losses and explored the tilt angle effect on the soiling losses by doing soiling experiments. Shirazi et al., proposed an integrated techno-economic evaluation tool to identify the most appropriate PV installation façades in urban areas in Tehran, Iran [64]. They found that the proper selection of the angles and building façades for installing PV panels could significantly increase the solar power production and the internal rate of return. Huang et al., developed an iterative method based on a genetic algorithm to optimize the capacity and positions of PV modules at the cluster level, with the purpose of maximizing the self-consumed electricity under a non-negative net present value during the economic lifetime [41]. Boeckl and Kienberger developed a Fourier series approximation-based method for sizing a grid-connected PV storage system to maximize solar energy self-utilization [65].

\subsubsection{Electric and Thermal Energy Demand}

The energy demand modeling approaches for buildings can be roughly divided into physical modeling [66] and statistical modeling [67]. Physical models are mathematical representations of heat and mass transfer phenomena between buildings, people, and the environment. For instance, Palacios-Garcia et al. [68] developed a high-resolution model for calculating the electricity demand of heating and cooling appliances, considering variables such as the number of residents, location, type of day (weekday or weekend) and date. In [69], a model for simulating lighting power consumption profiles in Spain was developed, considering the number of household residents and differentiating between weekdays and weekends. In [70], Widén developed a model for computing the occupancy and electricity load in Sweden. Physics-based models usually report high accuracy at the expense of high degrees of complexity and data requirements. Statistical models are mathematical representations of the relationship between an observed set of historical variables. In [71], a systematic review of the regression analysis-based statistical modeling approach was conducted. A simple and multiple linear regression analysis along with a quadratic regression analysis were analyzed and compared. In [72], a systematic review of the data-driven statistical modeling approach was conducted. The data-driven statistical modeling approach was further classified into artificial neural network-based approaches, clustering-based approaches, statistical and machine learning-based approaches, and support vector machine-based approaches. Statistical models offer a more parsimonious modeling alternative at the expense of detailed physical explanatory power.

\subsubsection{Electric and Thermal Energy Storage}

Generally, there are two main potential storage technologies: electrical and thermal energy storage. Specifically, electrical energy storage is able to provide operational flexibility among a building cluster, regulating the power to fit a building's demands and enhancing the energy self-sufficiency. Thermal energy storage stores the energy in the form of thermal energy (e.g., heat). Similarly, thermal energy storage can overcome, in the short term, hourly, daily or weekly mismatches, while, in the long term, it can overcome seasonal variations between renewable energy supply and demand, maximizing the synergies among the buildings in a cluster. 
Some of the studies have been focused on thermal energy storage. As an example, Hsieh et al., evaluated the performance of different storage configurations to a cluster scale of 11 buildings in Switzerland [73]. Specifically, the energy derived from the solar thermal collectors is assumed to cover the energy demand (hot water and space heating) of the buildings, while different configurations of thermal energy storage (long and short term) are included to overcome a period during which there is not enough solar thermal energy available. Rodríguez et al., explored the potential of alleviating the energy poverty for a low-income housing district in Spain, by using a PV-heat pump-thermal mass storage system [74]. The surplus PV power is used to power the heat pumps, which provides heating/cooling to all dwellings, increasing the occupants' thermal comfort. In this study, the thermal mass storage capacity of the buildings themselves was used. Huang et al., developed an advanced energy-matching concept to improve building cluster performance [41]. In this study, a hot water storage is supposed to store the excess PV energy in the form of heat. Specifically, the excess PV electricity power is transmitted to the heat pump to produce heating energy, and the produced heat is stored as hot water.

Some studies have focused on electrical energy storage. For instance, Roberts et al., analyzed the impacts of applying a Battery Energy Storage Systems (BESS) in terms of increased PV-self consumption, maximized self-sufficiency and reduced peak demand in several apartments in Australia [75]. It was pointed out that embedded networks with PV-BESS in the building cluster could have a beneficial effect on the network distribution due to the reduced daytime export and evening peak demand. However, due to the current battery energy storage system tariffs and costs, the usage of thermal energy storage systems could be a more financially attractive method to store the excess energy produced by $\mathrm{PV}$ at a building cluster level. Koskela et al., analyzed, from an economic perspective, the profitability of a PV system with an associated electrical energy storage system for apartment buildings forming an energy community [76]. The study highlighted the necessity of firstly sizing the electrical storage in order to have a profitable PV system size, leading to an increased amount of PV production in the residential sector. In the UK, Parra et al., found that the application of community energy storage was a good solution to facilitate the usage of distributed renewable energy generation and manage the demand loads [77]. Specifically, the authors quantified the performance of lead-acid $(\mathrm{PbA})$ and lithium-ion (Li-ion) batteries performing demand load as a function of the size of the community by using simulation-based optimization. In a similar study, Parra et al., found that community energy storage reduced the levelized cost of energy storage by $37 \%$ by performing a PV energy time shift [78]. Finally, Sardi et al., presented an analytical framework for community energy storage integration in an existing residential system with a rooftop PV unit [79].

\subsection{EV Side Modeling}

\subsubsection{EV Demand Modeling}

The EVs adopt high-density lithium-ion batteries, which require the least maintenance relatively, and are less susceptible to memory effects and flexible cycling [80]. The subcompact EVs use batteries with a power capacity of $12 \sim 18 \mathrm{~kW} \cdot \mathrm{h}$; mid-sized family sedans use batteries with a capacity of $22 \sim 50 \mathrm{~kW} \cdot \mathrm{h}$, and luxury models, such as those from Tesla, employ batteries with a capacity of $60 \sim 85 \mathrm{~kW} \cdot \mathrm{h}$ [81]. Battery capacity usually degrades over charging/discharging cycles. Factors such as charging rate, environment temperature, battery management and charging behavior will affect the battery life and hence the EV range. As reported by Hall et al., a 100\% discharge of the battery should be avoided to ensure the maximum battery life cycle; otherwise, battery wear and calendar fade (i.e., battery performance deteriorates over time whether the battery is used or not) can occur due to a high state of charge (SOC) [82].

Many studies have been conducted to investigate EV energy usage patterns and estimate EV load profiles. Some of the studies extract EV usage patterns from real data. For instance, based on a Dutch mobility study, Geth et al., rebuilt the probability distributions for work traffic, work shifts, 
and population activity for Belgium [83]. Information about driving trips, such as motivation, time of day and distance are collected and used for generating driving profiles, which have a one-minute resolution and are available for both workdays and weekends. Lee et al., synthesized representative naturalistic cycles of EV behavior through a stochastic process, utilizing transition probability matrices extracted from naturalistic driving data collected in the Midwest region of the United States [84]. Using the real data on mobility behavior in Germany 'Mobilität in Deutschland', Fischer et al., first analyzed the impacts of a set of factors (e.g., the household type household economy status, place of residence, driver occupation, week day, trip index and trip purpose) on the driving behavior (e.g., car use pattern, car trips per day, trip purpose, distance and driving time, first departure time and parking time) [85]. After identifying the most influential factors, they modeled the EV use with an inhomogeneous Markov chain to sample a sequence of destinations from each car trip, depending (among other factors) on the occupation of the driver, the weekday and the time of day. Lojowska et al., derived the stochastic characteristics of the EV behavior of vehicles (including the start/end-time of each trip, the respective travelled distance and battery state of charge) using a detailed transportation dataset for the Netherlands [86]. Then, a Monte Carlo simulation-based approach was used for calculating the power demand of EVs under the scenario of uncontrolled domestic charging.

Based on the charging behavior of drivers, researchers have also developed advanced decision models for EV charging, such as Markov chain decision models and fuzzy logic inference models [87]. For instance, Moreira et al., simulated the EV movement across a one-year period by using a discrete-state, discrete-time Markov chain to define the states of an EV with a timestep of $30 \mathrm{~min}$ [88]. At every unit of time, the model assumes the EV to be in one of the four event states: in movement, parked in a residential area, parked in a commercial area, and parked in an industrial area. By combining EV usage with the synthetic activity generation of occupants' electricity-dependent activities, Grahn et al., used a Markov chain model to generate plug-in hybrid electric vehicles' (PHEVs) home charging patterns [89]. The synthetic activity data were simulated based on time use data collected in time diaries, and they define the basis for calculating PHEV home-charging behavior as well as a resident's electricity consumption. Shahidinejad et al., adopted a fuzzy logic inference system to emulate EV battery charging based on a large field-recorded driving database [87]. The fuzzy inference assumes that the state of charge (SOC) of the battery and estimated parking duration are the two main factors that govern a driver's decision whether or not to charge when a plug-in vehicle is to be parked, as it is considered that the driver needs to be confident that for the next trip the battery has an adequate SOC.

Researchers have also developed some statistical models based on probability distributions derived from real data. For instance, based on the same EV home-charging model as [89], Munkhammar et al., developed a probability distribution model by merging it with another two separate existing probability distribution models (i.e., for calculating household power consumption and PV power production) [90]. Using the probability distribution model, the distributions of the power consumption/production mismatch were investigated on both the household level and on the aggregated level of multiple households. Darabi and Ferdowsi extracted the probability density functions of the start time of EV charging, the required electrical energy and required power using the available data from American national household travel surveys [91]. A similar modeling approach was conducted by Remco et al., for the Netherlands scenario [92] and by David et al., for the Germany scenario [93].

For a large number of EV units, Islam et al., developed a combined SOC-based methodology to calculate day-ahead combined probabilistic charging loads [94]. Instead of managing the charging rate of every EV separately, their proposed model charges EVs with a lower SOC level at a higher rate, and vice versa. Islam et al., also proposed a correlated probabilistic model for EV charging loads in coordination with a solar PV-rich commercial grid [95]. In their proposed model, correlated samples are first generated from uncorrelated samples containing a wide range of random variables associated with EV loads, PV outputs, battery energy storage powers, and grid loads. 


\subsubsection{Design/Plan of EV Charging Stations}

Existing studies have developed a number of methods to optimize the design and planning of renewable powered charging stations in cities. For instance, Luo et al., developed a comprehensive optimization model concerning the joint planning of distributed generators and EV charging stations, which involves spatially dispatchable characteristic at the planning stage of distribution systems and deploys power devices in a cost-effective way [96]. The proposed model is embedded with the spatial scheduling problem of EV charging demands and focuses on the optimum relevant social costs. Notably, Huang et al., developed a Geographic Information System (GIS)-assisted optimal design method for renewably (i.e., generated by roof-mounted PV systems) powered EV charging stations in high-density cities [11]. Using the GIS technique, their method first discretizes the studied district into equally sized grids and collects the geographic information of massive buildings in each grid. Then, the roof-based solar energy potential in each grid is estimated. Next, the optimal locations and an optimal number of renewable powered charging stations are searched by the genetic algorithm with the consideration of the existing charging stations and renewable potentials. The design method can be used in practice to help high-density cities build their renewable-powered public charging networks with cost-effectiveness. Notably, Morrissey et al., performed an analysis of the charge event data for public charging infrastructure and household charging stations in Ireland [97]. They found that EV users prefer to carry out the majority of their charging at home in the evening during the period of highest demand on the electrical grid, thus implying that incentivization may be required to shift charging away from this peak grid demand period. They also reported the popularity of using fast chargers in the car park locations and thus concluded that priority should be given to developing a highly connected network of strategically located fast chargers.

\subsection{Grid Modeling}

\subsubsection{Overall Power Grid Architecture}

Renewable energy systems, buildings (as electricity end-users), energy storage systems and EVs are essential players in the smart grid. Based on an extended NIST model [98], Chaouachi et al., proposed a conceptual architecture of the modern smart grid, from an interoperability and functionality prospective, to enable decentralized operational synergy between intermittent PV generation and EVs, based on coordinated EV charging, as shown in Figure 6 [46]. The conceptual architecture consists of several domains (i.e., distribution, distributed energy resource (DER) and consumption) and zones (i.e., enterprise, operation, station, field and process). The domain dimension is partitioned by the electric distribution conversion chain that includes the distribution operation, DER and prosumers. The zone dimension refers to the hierarchical system aspects spanning the whole smart grid [99].

- The process zone contains the primary set of equipment associated to the physical layer of the electricity network.

- The field zone contains the auxiliary equipment that are committed to the control and monitoring of the electricity networks.

- The station zone is mainly characterized by the station controllers and Customer Energy Manager (CEM). The CEM optimize its client's energy consumption and/or production based on signals received from the grid, consumer's settings, home area network (HAN) and contracts.

- The operation zone includes energy management aggregators (EMA) offering services to aggregate energy production and controllable loads.

- The enterprise zone is at the highest hierarchical level. It includes the commercial and organizational processes, such as utilities power scheduling, service providers and energy traders. There can be some overlap between the operational and the enterprise zone. 


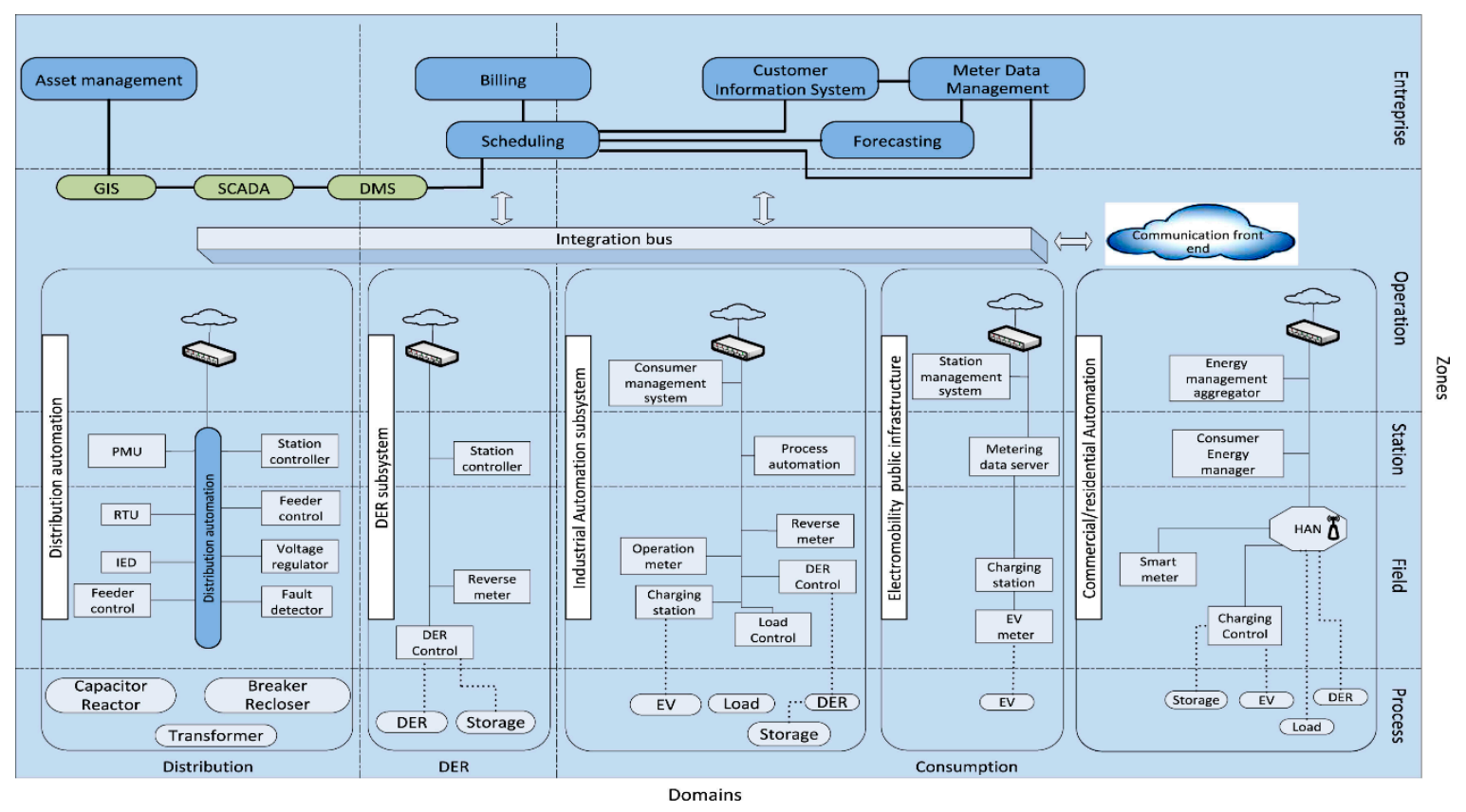

Figure 6. Smart grid conceptual architecture for enhanced solar mobility [46].

In the enterprise and operation zones, all the equipment can interact with each other using the existing technology, which is compliant with the relevant communication standards [100,101]. For the local sub-networks in the field and station zones, which directly integrate the communication channels between EVs, DERs, smart appliances and controllable loads, decentralized bidirectional communication and more interfacing flexibility are required to coordinate with other entities of the smart grid via high-level communication protocols. Such communication architecture would have the potential to convey and relay data through intermediate devices, creating a meshed network without the requirement for centralized control [46,99].

\subsubsection{Local Microgrid Structure}

Considering the complexity of the system in the future, a more decentralized operation could simplify the task of grid operation by seamless prosumer involvement. In fact, emerging distribution systems are planned to integrate plug-and-play devices, enabling a set of new functionalities related to the various actors (retailers, distribution system operators (DSO), aggregator, prosumers, etc.) and implemented through various technologies (generation devices, loads, communication, etc.) in which it will be possible to efficiently exchange information and commands [102]. The end users specifically need to incorporate smart appliances capable of communicating their status and auto-adjusting their operation based on their requirement and/or the DSO/retailers' provided set points (when relevant) [46].

With reference to a number of studies introducing the new electricity network [41,103,104], a generic power distribution network, which represents the future development trend of micro power network for multiple energy prosumers and the public charging stations, is summarized in this study, as shown in Figure 7. The energy prosumers are equipped with their own renewable energy systems, electrical storage, EVs and other electrical appliances. The buildings are connected into a renewable energy sharing microgrid, in which the surplus renewable production can be delivered from one building to another. Such a renewable energy sharing microgrid provides a platform for the buildings in the cluster to share their surplus renewable energy generations with other buildings, thus helping enhance the overall cluster-level performance. The central systems, such as central electrical battery/thermal energy storage and district heating systems, are also connected to the energy sharing micro power grid. The energy sharing microgrid is also connected to the power grid, in case surplus/insufficient cluster-level renewable generations and electricity exchanges with the power 
grid are needed. The power exchange of the building cluster with the power grid is metered by advanced metering facilities. The micro power grid can be either a direct current (DC) power grid or an alternating current (AC) power grid. Proper inverters/converters are needed, corresponding to the different microgrids used.

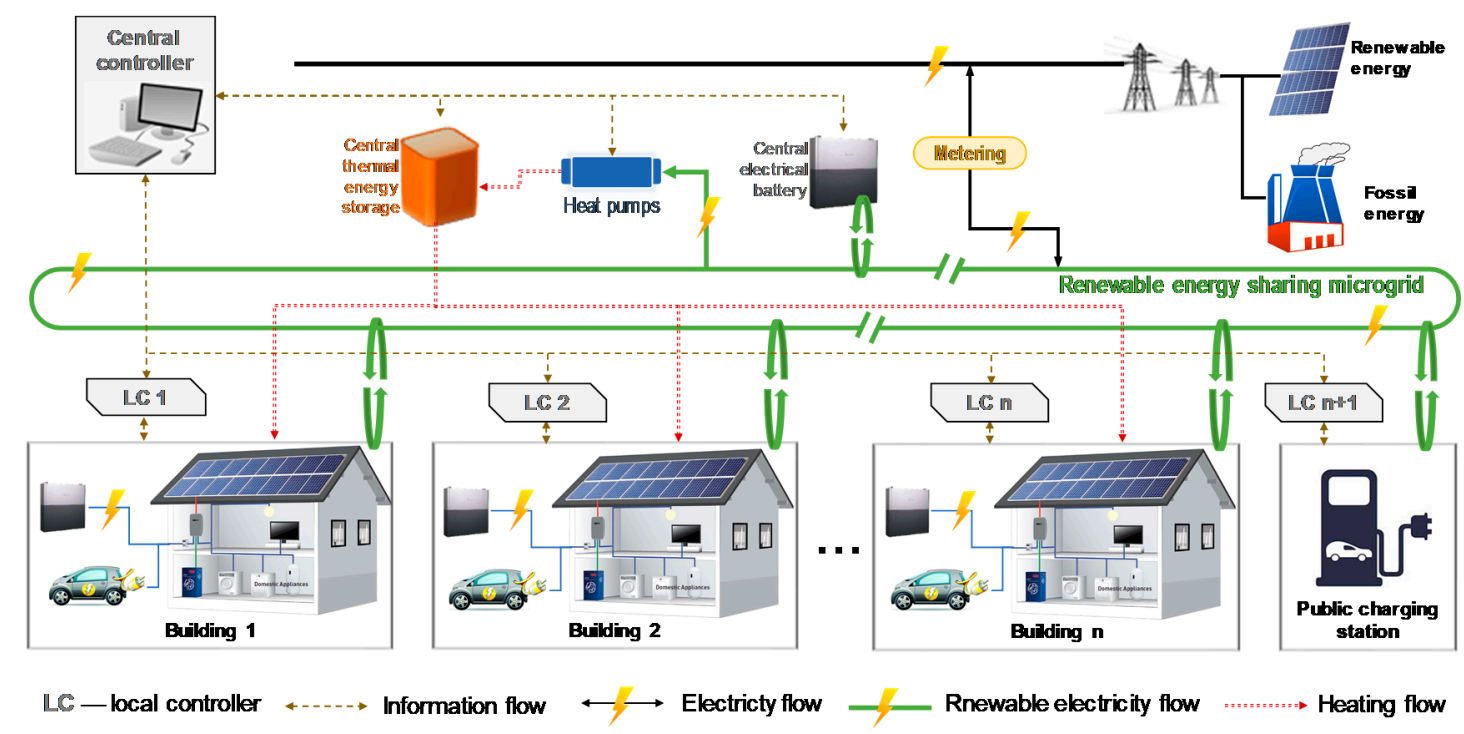

Figure 7. Structure of energy sharing network.

Each building has a local controller to manage its own storage charging/discharging as well as the flexible electrical loads. The public charging station also has a local controller, which is able to manage and optimize its power flow. All the local controls are connected to a central controller for coordinating the operation of each building and the public charging station and regulating the renewable energy sharing within the micro power grid.

\subsubsection{Energy Sharing Networks}

Renewable energy sharing inside the building cluster is a promising way to enhance the building cluster-level renewable energy self-utilization rates and reduce the impacts of large building electricity demand penetration on the power grid. To enable such energy sharing, a specific energy sharing network is needed for the power transmission between different buildings. The PV panels, the battery storage, and many modern large loads, such as pumps, compressors, fans, servers and EVs, often operate with DC power. DC/AC conversion at both the supply side and demand side not only causes dramatic electricity losses, but also reduces the system reliability due to increased complexity [41]. To address these issues, some researchers have recommended using DC microgrids for renewable energy sharing between buildings, instead of using AC microgrids. Chen et al., proposed a DC microgrid connecting a number of facilities including PV panels, wind turbines, battery storage and other electrical loads such as EVs [105]. A bi-directional inverter is used for connecting the microgrid with the public AC network. The installed DC bus has a voltage of $380 \mathrm{~V}$. Each module in the system communicates with the energy management system (EMS) based on RS-485 or a ZigBee communication protocol. The EMS commands the modules when to operate and collect operational status.

Ayai et al., proposed a DC microgrid system as a power network for introducing a large amount of solar energy using distributed PV generation units [106]. The installed DC bus has a voltage of $350 \mathrm{~V}$. They summarized the benefits of using a DC microgrid as follows: (1) increase the introduction of distributed PV units; (2) reduce energy dissipation and facility costs resulting from AC/DC conversion by integrating the junction between a commercial grid and DC bus which connects PV units and accumulators; and (3) supply power to loads via regular distribution lines (not exclusive lines for 
emergency) even during the blackout of commercial grids. Notably, Ferroamp developed an Energy Hub for DC microgrid power sharing [107]. The Energy Hub converts and controls the energy flow in both directions between the DC grid and the facility AC grid. The operating voltage of the DC microgrid is $760 \mathrm{~V}$. Loads that support a nominal DC voltage of $760 \mathrm{~V}$ can be powered directly from the DC grid. A minibus DC/DC converter has also been developed to step down the $760 \mathrm{~V}$ DC grid voltage to the output voltage required by other DC loads $(120-400 \mathrm{~V})$. The communication of the Energy Hub is based on the TCP/IP protocol.

\subsection{Advanced Controls}

Proper control is essential for a building energy system to achieve a good performance. Existing studies have developed a lot in relation to advanced controls for improving building energy systems' performance and promoting solar mobility. The existing controls can be clarified into two categories: individual controls and coordinated controls. The individual controls focus on a single building's operation and aim to optimize the single-building-level performance, while the coordinated controls focus on the coordination of multiple buildings' operation and take building cluster-level performance as the optimization object. The coordinated controls can be further classified into a bottom-up approach and a top-down approach, as summarized in Table 2. This section introduces the up-to-date controls for promoting solar mobility from these two aspects.

\subsubsection{Individual Controls}

Battery/thermal storage control: Aiming at reducing the carbon dioxide emission, primary energy consumptions and operation cost, Zhao et al., developed a model predictive control-based strategy to schedule the operation of the energy systems in a grid-connected low-energy building, which included a stratified chilled water storage tank, PV system, and distributed power generation units [108]. At the start of each day, the developed method uses a nonlinear programming algorithm to schedule the operation of a combined cooling and power system and the thermal energy storage in the coming $24 \mathrm{~h}$ under day-ahead electricity prices. Similarly, Lu et al., proposed an optimal scheduling method for building energy systems integrated with PV power generation, combined cooling, a power system and a thermal storage tank [109]. Each hour, the operation of the whole system in the coming $n$ hours (i.e., the time horizon) is optimized by a mixed-integer nonlinear programming algorithm, with the purpose of minimizing the operational costs. With parameter uncertainty (e.g., heat transfer coefficients, operational efficiency) considered, Allison developed a robust multi-objective nonlinear inversion-based control strategy for NZEBs equipped with a micro combined heating and power (CHP) unit, PV, and battery storage, to minimize the NZEB's grid power utilization while fulfilling the thermal demands [110]. Their developed controller combines the inverse dynamics of the building, servicing systems, and energy storage with a robust control method. The inverse dynamics provides the controller with knowledge of the complex cause and effect relationships between the system, controlled inputs and the external disturbances, while an outer-loop control ensures robust, stable control in the presence of modeling deficiencies/uncertainty and unknown disturbances.

EV charging control: Cai et al., derived a convex battery capacity loss model from a physical-based degradation model, to capture the battery aging cost [111]. Based on the developed model, they further proposed an aging-aware model predictive control approach, which takes account of the battery capacity degradation and its negative impacts on the costs, for optimized operation of sustainable buildings with on-site PV and battery systems. Considering the stochastic charging behavior, Islam et al., developed a coordinated EV charging method based on a correlated probabilistic model of EV charging loads [95]. The charging control optimizes the power factors of PV and battery energy storage system to enhance the quality of service (QoS) while minimizing the probability of voltage and current noncompliance (PVCN). The developed control strategy was tested on a three-phase IEEE 37-bus imbalanced distribution system using the real data of vehicles and solar PV. Their developed control is effective in providing more quality of service. 
Table 2. Classification of the existing energy storage and EV controls related to solar mobility.

\begin{tabular}{|c|c|c|c|c|c|}
\hline \multicolumn{2}{|c|}{ Category } & \multirow[b]{2}{*}{$\begin{array}{l}\text { Principal } \\
\text { The operations of individual energy storage/the } \\
\text { charging rates of individual EVs are first optimized } \\
\text { separately. Then, the individual energy storage } \\
\text { performances/EV charging loads are aggregated to } \\
\text { obtain the aggregated level performance. }\end{array}$} & \multirow{2}{*}{$\begin{array}{c}\text { Pros } \\
\text { Easy to implement }\end{array}$} & \multirow[b]{2}{*}{$\begin{array}{l}\text { Cons } \\
\text { 1. The aggregated level performance is } \\
\text { not optimized. } \\
\text { 2. New demand peaks may occur when } \\
\text { individual energy storage systems/EV } \\
\text { take the same action (e.g., shift demand } \\
\text { to the same period) }\end{array}$} & \multirow{2}{*}{\begin{tabular}{l}
\multicolumn{1}{c}{ Examples } \\
Energy storage \\
controls: [108-110]; \\
EV controls: \\
[94,95,111,112].
\end{tabular}} \\
\hline $\begin{array}{l}\text { Individual } \\
\text { controls }\end{array}$ & $\begin{array}{l}\text { Individual } \\
\text { approach }\end{array}$ & & & & \\
\hline \multirow{2}{*}{$\begin{array}{l}\text { Coordinated } \\
\text { controls }\end{array}$} & $\begin{array}{l}\text { Bottom-up } \\
\text { approach }\end{array}$ & $\begin{array}{l}\text { The operations of individual energy storage/the } \\
\text { charging rates of individual EVs are optimized one } \\
\text { by one in a sequence, and the optimization of each } \\
\text { single energy storage system/EV's operation is } \\
\text { performed based on the aggregated results of the } \\
\text { earlier optimized energy storage/EVs. }\end{array}$ & $\begin{array}{l}\text { Better performance at } \\
\text { aggregated level than } \\
\text { individual approach }\end{array}$ & $\begin{array}{l}\text { 1. The aggregated magnitude becomes } \\
\text { increasingly large after many } \\
\text { optimizations, leading to the subsequent } \\
\text { optimization being less effective in } \\
\text { improving the aggregated level } \\
\text { performance and non-optimal solution. } \\
\text { 2. High computational load. }\end{array}$ & $\begin{array}{l}\text { Energy storage } \\
\text { controls: }[104,113,114] \\
\text { EV controls: } \\
{[115,116] .}\end{array}$ \\
\hline & $\begin{array}{l}\text { Top-down } \\
\text { approach }\end{array}$ & $\begin{array}{l}\text { The aggregated level performance is directly used as } \\
\text { the optimization objective. The operations of } \\
\text { individual energy storage/the charging rates of } \\
\text { individual EVs are coordinated to achieve the } \\
\text { obtained performance at the aggregated level. }\end{array}$ & $\begin{array}{l}\text { Optimized performance at } \\
\text { aggregated level }\end{array}$ & $\begin{array}{l}\text { The computational complexity increases } \\
\text { with the number of energy storage } \\
\text { systems/EVs. }\end{array}$ & $\begin{array}{l}\text { Energy storage } \\
\text { controls: }[24,40,103] \\
\text { EV controls: }[44,47,83]\end{array}$ \\
\hline
\end{tabular}


These non-coordinated battery/thermal storage/EV controls can effectively increase the individual building's renewable energy self-consumption and reduce the peak demands as well as the electricity costs. However, since these controls focused on an individual building's performance optimization, the aggregated performances at the building cluster level are not optimized.

\subsubsection{Coordinated Controls}

Battery/thermal storage control: Regarding renewable energy sharing among different buildings, Prasad and Dusparic developed a Deep Reinforcement Learning (i.e., a machine learning approach that enables intelligent agents to learn the optimal behavior via trial and error)-based method for the ZEB community, with the purpose of reducing energy losses due to transmission and storage, and achieving economic gains [114]. Fan et al., also developed a collaborative DR control of zero energy buildings for building group performance improvements, in which the control of each building was conducted in sequence, and the optimization of one building's operation was based on the previously optimized buildings' operation, i.e., the optimization of $(k+1)$ th building's operation is based on the aggregated operation of the first to kth buildings [113]. A genetic algorithm is used in the optimization of each individual building: the daily hourly charging/discharging rates of the battery are set as variables to be optimized, and the economic cost and grid friendliness are set as the objective function. The abovementioned controls can significantly improve the building cluster performances by the proper coordination of individual buildings and enabling energy sharing among them. However, these controls optimize the building cluster performance in a bottom-up way, and they merely perform very limited collaborations among buildings. Aiming at maximizing the benefits of collaboration among buildings, Huang et al., developed a two-level top-down control for a cluster of buildings equipped with renewable energy systems and electrical energy storage system [103]. In their study, the whole building cluster is first considered as a 'virtual' building, and its electrical battery charging/discharging rates is optimized using the genetic algorithm. Then, based on the optimized performances at the building cluster level, the operation of every single building inside the cluster is coordinated using a non-linear programming algorithm. Similarly, Odonkor et al., developed a control method for NZEBs using a genetic algorithm and Pareto decision making based on an adaptive bi-level decision model (with a facilitator agent at the cluster level and local systems at the single NZEB level) [104]. Considering the dynamic pricing, in [24] a similar three-step iterative demand response control algorithm is developed. Taking into account the uncertainty in PV production and renewable energy sharing among different buildings, Zhang et al., developed a two-stage adaptive robust optimization-based collaborative operation approach for a residential multi-microgrid to derive the scheduling scheme, with the purpose of minimizing multiple microgrids' operating costs under the worst realization of uncertain PV output [40].

EV charging control: Regarding EV coordinated charging control, Ma et al., proposed a multi-party energy management method for an NZEB cluster based on non-cooperative game theory [115]. They proved the existence of Nash equilibrium in the game model and modeled the process for solving the Nash equilibrium strategy as a multi-objective optimization problem (MOP). Their study results show that the proposed method can reduce the total cost of smart buildings by $4.6 \%$ and improve the load factor of a smart building cluster from 0.68 to 0.76 . Geth et al., developed a coordinated charging for a number of EVs [83]. In the developed coordinated control, a vehicle owner first indicates the point in time when the batteries should be fully charged. Then, the aggregator collects this information and calculates when each PHEV can start charging. Usman et al., proposed an automated coordinated control of EV fleets, which can plan the charging strategy at the cheaper moments and keep the vehicle charged enough to complete its scheduled trips [116]. Islam and Mithulananthan proposed a method that utilizes the measured PV output of a given sample and the supplied historical ramp to predict the PV output of the next immediate sample based on a non-iterative method [47]. Based on the predicted PV output, they developed an SOC-based charging strategy for EVs, which adjusts the charging rates of the EV population in the intervals between successive samples. 
Taking advantage of their charging/discharging ability, EVs can be used as flexible voltage or frequency regulation services. Zhong et al., proposed a coordinated control strategy for large-scale EVs, battery energy storage stations (BESSs) and traditional frequency regulation resources involved in automatic generation control [117]. According to the magnitude of area control error (ACE), i.e., the difference between the scheduled and actual power generation within a control area on the power grid, and ACE duration, different actions (e.g., operating the BESSs or operating the EVs) will be taken by the controller. With the purpose of regulating the power network voltage, Li et al., developed a model predictive control method for a number of EVs [118]. Their study results show that the developed method can effectively regulate the grid power voltage. Meanwhile, according to the size of the connected EVs, the EVs can assist or even replace the traditional reactive power compensation device to maintain the grid voltage within a stable range while satisfying its own charging requirements. Similarly, Jia et al., developed a coordinated control strategy for EVs and power plants in frequency regulation [119]. They defined a robust stability criterion to determine the delay margin of a frequency control system. Su et al., developed a stochastic microgrid energy scheduling method, which aims at minimizing the expected operational cost of the microgrid and power losses by optimally dispatching the EV charging load and scheduling distributed generators (DGs) and distributed energy storage devices (DESDs) [45]. Chaouachi et al., proposed a conceptual architecture of a smart grid to enable decentralized operational synergy between intermittent PV generation and EVs, based on coordinated EV charging [46]. Relying upon the proposed smart grid conceptual architecture, they also developed an assessment framework to maximize the renewable electricity and EV penetration for given electricity and transport systems. Dallinger et al., developed a method to characterize the fluctuating electricity generation of renewable energy sources (RESs) in a power system and compared the different parameters for California and Germany [44].

\section{Simulation Platforms and Performance Metrics}

This section reviews the simulation platforms and performance metrics for solar mobility studies.

\subsection{Potential Modeling Platform for S2BVS}

This section reviews some modeling platforms for S2VBS systems and categorizes them into three aspects based on their functions: modeling software for the demand/supply of buildings, for powerline/power grid (related to distribution network) and for advanced controls.

\subsubsection{Modeling Platforms for the Demand/Supply of Buildings}

Buildings and PV systems are two vital components in S2VBS systems. This subsection mainly introduces several modeling platforms for building load profiles and PV-generated energy.

- Hybrid Optimization Model for Electric Renewables (HOMER) software is a widely used software for both grid-connected and off-grid energy systems for various applications. Based on HOMER, researchers can conduct sensitivity analysis and optimization for systems. They can also process operation and maintenance, capital and interest cost calculations. In recent years, many studies have adopted HOMER for analyzing and optimizing renewable energy systems. Kumar et al., applied HOMER to study the feasibility of a standalone solar-wind-diesel hybrid power system for an ATM machine in remote areas [120]. Abdul-Wahab et al., employed HOMER to find the best PV system for Oman's conditions [61]. Li et al., assessed the feasibility of a hybrid PV/diesel/battery power system in the suburb of Harbin in China using HOMER [121].

- Transient System Simulation (TRNSYS) is adopted for modeling the supply of renewable energy sources, like PV or wind power, and the use of multi-zone buildings, including heating, ventilation and air-conditioning (HVAC) systems or other systems. An advantageous characteristic of TRNSYS is that submodules can be added in programming languages by users themselves, e.g., by Fortran [122]. Another advantage of TRNSYS is how flexibly it can be coupled with other tools 
such as Matlab for co-simulation, which enables optimization [123]. In a recent study, Jonas et al., developed a user-friendly simulation model of solar and heat pump (SHP) systems for people with less professional knowledge [124]. Saleem et al., simulated a solar water heating system and a solar-hydrogen hybrid energy system through TRNSYS [125]. Furthermore, TRNSYS was also used for modeling a building-integrated solar thermal system with seasonal thermal energy storage by Antoniadis and Martinopoulos [126].

- EnergyPlus is a whole-building energy simulation program that is used for both energy consumption and water use in buildings, especially for the loads of buildings with HVAC systems or multiple thermal zones. It is a standalone software that reads inputs and completes outputs to text files. Uygun et al., studied the influence of building-integrated PV solutions on the performance of a residential building in Anatolia by EnergyPlus [127]. Apart from dwelling buildings, Boyano et al., used EnergyPlus to model the energy consumption traits of office buildings in different climate zones and advised some feasible ways for energy savings related to the main energy consumption end uses [128]. Bingham et al., studied the optimization of a grid-connected residential building with PV and battery storage systems in EnergyPlus [129].

\subsubsection{Modeling Platform for Powerline/Power Grid}

This subsection primarily lists some modeling tools related to electricity and distribution.

- The Open Distribution System Simulator (OpenDSS) is a commonly used simulation tool for multiphase distribution systems. Users can define their required components into OpenDSS by setting certain parameters and then gain an extensive range of simulating conditions. Ke et al., carried out a study by adopting OpenDSS to establish a power distribution system model and the charge/discharge of a future battery energy storage system [130]. Another piece of research studied the power quality measurement of EV battery charging in Finland [131]. From the distribution network point of view, they chose OpenDSS to simulate the harmonic current flow of EV charging and form the network. Ahamioje and Krishnaswami considered the voltage fluctuations and frequency variations generated by the high penetration of PV in grid power [132]. Then, they employed OpenDSS with Matlab to implement advanced inverter functionalities.

\subsubsection{Modeling Platform for Advanced Controls}

This subsection introduces some modeling platforms for implementing solar mobility-related controls.

- Matlab is one of the graphical tools that have been developed in computer technology. Today, the applications of it extend extensively, including the simulation of a whole system or a small part. Several different applications of Matlab, especially for controlling modules, are discussed below. In Papas et al.'s study, Matlab was used to simulate the global functioning of a building installed with PVs and HVAC systems [133]. Another study modeled a standalone PV system with the combination of two pieces of software, PSIM and Matlab [134]. Matlab was used for simulating the control circuit. Bava and Furbo developed a co-simulation between TRNSYS and Matlab for a solar collector field [123].

- CPLEX is usually for linear programming [135]. The efficiency and robustness of its algorithm have been demonstrated in solving mathematic problems in multiple areas. In relevant studies, CPLEX has been widely adopted when researchers solve EV routing problems and simulate the stochastic distribution of EVs. Zuo et al., took a charge station into account and tried to develop a mathematical model for solving the EV routing problem based on CPLEX [136]. Zakaria et al., conducted a study to compare CPLEX and a greedy algorithm when given the problem of modeling car relocation [137]. In S2VBS systems, when there is a need to simulate the routes of EVs between buildings and network maps of the whole system, CPLEX has its advantages in terms of linear programming and processing stochastic data. 
There is also other software available (GAMS, Pyomo, etc.) for modeling and optimization. These types of software are not set up specifically for solar mobility problems, so they have significant drawbacks in the amount of effort required in setting up simulations for that purpose. For software that is specific designed for building energy demand/supply modeling, such as EnergyPlus, TRNSYS and HOMER, there are typically built-in libraries and data available, which can reduce the model construction efforts. Software such as Matlab and CPLEX do not have built-in libraries and data available. However, the internal solver, such as a genetic algorithm and non-linear programming, can be used to reduce the efforts in programming the algorithm.

\subsection{Metrics as Optimization Objectives of S2BVS Models}

This section reviews the popular metrics that can be used in the assessment of S2BVS models from three aspects: energy, economy, and environment. Table 3 summarizes the major performance metrics for a performance assessment of the S2BVS model. 
Table 3. Summary of the key performance metrics for performance assessment of the solar-to-buildings, vehicles and storage (S2BVS) model.

\begin{tabular}{|c|c|c|c|}
\hline Name & Calculation & Remarks on Calculation & Representation/Meaning \\
\hline \multicolumn{4}{|c|}{ Energy-Related Indicators } \\
\hline $\begin{array}{l}\text { Loss of power } \\
\text { supply possibility } \\
\text { (LPSP) [49] }\end{array}$ & $\operatorname{LPSP}=\frac{\sum_{t=1}^{T} \operatorname{LPS}(t)}{\sum_{t=1}^{T} P_{\text {load }}(t)}$ & $\begin{array}{l}\text { LPS: loss of power supply; } \\
P_{\text {load }}: \text { the load demand power. }\end{array}$ & $\begin{array}{l}\text { This is defined as the ratio of the loss of energy } \\
\text { supply to the load demand during the } \\
\text { considered period. }\end{array}$ \\
\hline $\begin{array}{l}\text { Potential energy } \\
\text { waste possibility } \\
\text { (PEWP) [49] }\end{array}$ & $\mathrm{PEWP}=\frac{\sum_{t=1}^{T}\left[P_{P V}(t)-P_{\text {load }}(t)-P_{\text {bat }}(t)-P_{\text {ele }}(t)\right]}{\sum_{t=1}^{T} P_{P V}(t)}$ & $\begin{array}{l}P_{P V}: \text { the power of PV array; } \\
P_{\text {load }}: \text { the load demand power; } \\
P_{b a t}: \text { the power of retailed EV batteries; } \\
P_{e l e}: \text { the power of the electrolyzer. }\end{array}$ & $\begin{array}{l}\text { This is defined as the ratio of the excess power to } \\
\text { the potential PV output power during the } \\
\text { considered period. }\end{array}$ \\
\hline $\begin{array}{l}\text { Capacity factor } \\
\text { (Cf) [138] }\end{array}$ & $\mathrm{Cf}_{\mathrm{pv}}=\left\{\frac{\sum_{t=1}^{8760} P_{p v}(t)}{8760 \times P_{\text {pvrated }}}\right\}$ & $\begin{array}{l}P_{P V(t)}: \text { the generated power at time } \mathrm{t} \\
P_{\text {pvrated }}: \text { assumed } \mathrm{PV} \text { generator capacity. }\end{array}$ & $\begin{array}{l}\text { This measures the energy production efficiency of } \\
\text { the facility over a period based on the solar } \\
\text { potential of a local site. }\end{array}$ \\
\hline $\begin{array}{l}\text { Capacity factor ratio } \\
\left(\mathrm{r}_{\mathrm{cf}}\right)[44]\end{array}$ & $\mathrm{r}_{\mathrm{cf} 0.8}=\frac{c f_{\text {Quantile }<0.8}}{c f_{\text {Quantile } \geq 0.8}}$ & $\begin{array}{l}c f_{Q}<0.8: \text { sorted power values smaller than the } \\
0.8 \text { quantile; } \\
c f_{Q} \geq 0.8: \text { sorted power values equal to and bigger } \\
\text { than } 0.8 \text { quantile. }\end{array}$ & $\begin{array}{l}\text { This allows for a more detailed analysis of the } \\
\text { energy availability. }\end{array}$ \\
\hline $\begin{array}{l}\text { Self-sufficiency } \\
\quad \text { (SS) [65] }\end{array}$ & $S C=\frac{E_{p v, \text { onsite }}}{E_{p v, \text { onsite }}+E_{p v, o f f \text { site }}}$ & 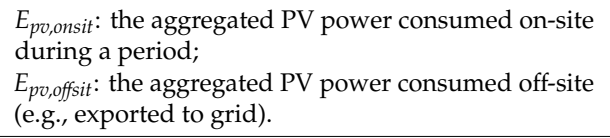 & $\begin{array}{l}\text { This shows how much less energy is needed from } \\
\text { the conventional power mix from the grid. }\end{array}$ \\
\hline $\begin{array}{l}\text { Self-consumption } \\
\quad \text { (SC) [50] }\end{array}$ & $S S=\frac{E_{p v, \text { onsite }}}{E_{d, \text { whole }}}=\frac{E_{d, p v}}{E_{d, p v}+E_{d, g \text { rid }}}$ & $\begin{array}{l}E_{d, p v}: \text { the aggregated electricity demand supplied by } \\
\text { the } \mathrm{PV} \text { system during a period, equal to } E_{p v, \text { onsit; }} \\
E_{d, g r i d}: \text { the aggregated electricity demand supplied } \\
\text { by the power grid. The sum of them equals } E_{d, \text { whole }} \text {. }\end{array}$ & $\begin{array}{l}\text { This represents the percentage of electricity } \\
\text { produced by on-site PV system used within } \\
\text { the building. }\end{array}$ \\
\hline \multicolumn{4}{|c|}{ Economy-Related Indicators } \\
\hline $\begin{array}{l}\text { Cost of energy } \\
\text { (COE) [61] }\end{array}$ & $\mathrm{COE}=\frac{\text { Cost }_{\text {tot }}}{E_{\text {tot }}}$ & $\begin{array}{l}\text { Cost tot: total cost for generation of energy for } \\
\text { one year; } \\
E_{\text {tot: }} \text { total energy generated in one year. }\end{array}$ & This calculates the unit cost of generated energy. \\
\hline $\begin{array}{l}\text { Net present value } \\
\quad \text { (NPV) [50] }\end{array}$ & $\mathrm{NPV}=\sum_{i=1}^{N} \frac{E c S}{(1+d)^{i}}-I C$ & $\begin{array}{l}\text { EcS: yearly economic savings; } \\
\text { IC: the total capital investment cost; } \\
d \text { : discount rate. }\end{array}$ & $\begin{array}{l}\text { This is calculated as the difference between the } \\
\text { present value of cash inflows and the outflows } \\
\text { over a certain period. }\end{array}$ \\
\hline $\begin{array}{l}\text { Internal Rate of } \\
\text { Return (IRR) }\end{array}$ & $\left.N P V\right|_{\mathrm{d}=I R R}=0 \rightarrow I R R$ & $\begin{array}{l}\text { NPV: net present value; } \\
d \text { : discount rate. }\end{array}$ & $\begin{array}{l}\text { This is a discount rate that makes the NPV of all } \\
\text { cash flows from a project equal to zero. }\end{array}$ \\
\hline
\end{tabular}


Table 3. Cont

\begin{tabular}{|c|c|c|c|}
\hline Name & Calculation & Remarks on Calculation & Representation/Meaning \\
\hline $\begin{array}{l}\text { Levelized cost of } \\
\text { electricity } \\
\text { (LCOE) [139] }\end{array}$ & $\mathrm{LCOE}=\frac{I_{0}+\sum_{t=1}^{n} \frac{A_{t}}{(1+i)^{t}}}{\sum_{t=1}^{n} \frac{M_{e}}{(1+i)^{t}}}$ & $\begin{array}{l}I_{0}: \text { the investment; } \\
M_{e}: \text { the electricity output in year; } \\
A_{t}: \text { the annual total costs; } \\
i \text { : the interest rate (discount rate); } \\
n: \text { the economic lifetime in years; } \\
t: \text { the year of operation }(1,2, \ldots, \mathrm{n}) \text {. }\end{array}$ & $\begin{array}{l}\text { This is based on the concept that all costs over the } \\
\text { lifetime of an energy project are discounted to } \\
\text { their net present value in a money unit divided by } \\
\text { the discounted energy production. }\end{array}$ \\
\hline $\begin{array}{l}\text { Total operation cost } \\
\quad\left(C_{\text {total }}\right)[48]\end{array}$ & $C_{\text {tot }}=C_{\text {purchase }}+C_{E V}+C_{E S S}+C_{E V-o u t s i d e}-C_{\text {income }}$ & $\begin{array}{l}\mathrm{C}_{\text {purchase }} \text { : cost to purchase electricity from the grid; } \\
\mathrm{C}_{\mathrm{EV}} \text { : degradation cost of the EV battery; } \\
\mathrm{C}_{\mathrm{ESS}} \text { : cost of ESS battery; } \\
\mathrm{C}_{\mathrm{EV}-\text { outside }} \text { : degradation cost of EV battery due } \\
\text { to driving; } \\
\mathrm{C}_{\text {income }} \text { income from selling electricity to the grid }\end{array}$ & $\begin{array}{l}\text { This calculates residential household energy costs } \\
\text { by considering EVs in relation to driving usage, } \\
\text { EV and ESS battery degradation, and PV } \\
\text { energy supply. }\end{array}$ \\
\hline $\begin{array}{l}\text { Annualized cost of } \\
\text { system (ACS) [49] }\end{array}$ & $\mathrm{ACS}=C_{\text {acap }}+C_{\text {amain }}+C_{\text {arep }}$ & $\begin{array}{l}C_{\text {acap }}: \text { the annualized capital costs of PV panels, } \\
\text { retailed EV battery (REVBs), electrolyzer, and } \\
\text { hydrogen tank; } \\
C_{\text {amain }} \text { : the annualized maintenance costs of the } \\
\text { above components; } \\
C_{\text {arep }} \text { : the annualized replacement cost of REVBs, FC, } \\
\text { electrolyzer. }\end{array}$ & $\begin{array}{l}\text { This calculates the total cost of the whole system } \\
\text { per year. }\end{array}$ \\
\hline $\begin{array}{l}\text { Profitability Index } \\
\quad \text { (PI) [50] }\end{array}$ & $\mathrm{PI}=\frac{\sum_{i=1}^{N} \frac{E c S}{(1+d)^{i}}}{I C}$ & $\begin{array}{l}\text { EcS: yearly Economic Savings; } \\
\text { IC: the total capital investment cost; } \\
\text { d: discount rate. }\end{array}$ & $\begin{array}{l}\text { This assesses the profitability of the investment } \\
\text { and ranks the proposed layouts by quantifying the } \\
\text { amount of value created per unit of investment. }\end{array}$ \\
\hline \multicolumn{4}{|c|}{ Environment-Related Indicators } \\
\hline $\begin{array}{l}\text { Well to wheels } \\
\text { (WTW) [43] }\end{array}$ & 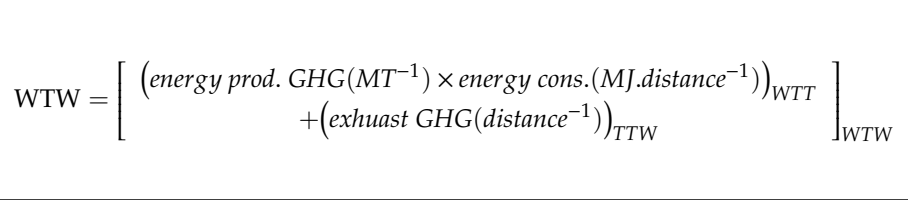 & $\begin{array}{l}\text { energy prod. GHG: greenhouse gas emission during } \\
\text { energy production; } \\
\text { energy cons.: Energy used for travelling a specific } \\
\text { amount of distance; } \\
\text { exhaust GHG: pollutant emissions by a car on a } \\
\text { given distance. }\end{array}$ & $\begin{array}{l}\text { This calculates the well-to-tank (WTT) stage which } \\
\text { covers the production of required energy and the } \\
\text { tank-to-wheels (TTW) stage covering the } \\
\text { consumption of energy and pollutant emissions by } \\
\text { a car over a given distance. }\end{array}$ \\
\hline $\begin{array}{l}\text { Carbon intensity } \\
\text { (CI) }[140]\end{array}$ & $\mathrm{CI}=\frac{e_{\text {total }}}{\mathrm{CF} \times c_{D C} \times t_{h r}}$ & $\begin{array}{l}e_{\text {total }}: \text { life cycle } \mathrm{GHG} \text { emissions }\left(\mathrm{gCO}_{2} \mathrm{e}\right) \\
C F: \text { capacity factor; } \\
c_{D C}: \text { rated DC capacity; } \\
t_{h r}: \text { PV system lifetime. }\end{array}$ & $\begin{array}{l}\text { This calculates the carbon emission of unit energy } \\
\text { consumption regarding the life cycle assessment. }\end{array}$ \\
\hline
\end{tabular}


Regarding energy performance assessment, loss of power supply possibility (LPSP) is one of the most commonly used metrics when assessing the possibility of lost power for the whole energy system. Huang et al., used LPSP to assess the energy system's reliability [49]. Huang et al., also used a metric, potential energy waste possibility (PEWP), to evaluate the energy usage efficiency of the modeled energy system. Capacity factor (CF) is the most widely used metric for assessing PV power generation. Adewuyi et al., analyzed the feasibility of implementing a solar power system in Nigeria by assessing the capacity factor [138]. Capacity factor ratio (rcf0.8), which is derived from capacity factor, allows for a more detailed analysis of the energy availability. Using this indicator, Dallinger et al., compared the integration of renewable energy sources (i.e., solar thermal collector, PV systems and wind turbines) in both California, U.S. and Germany [44]. Self-consumption (SC) is the annual average of the rate at which the electricity produced by the PV system is consumed on-site [141]. Huang et al., used SC to evaluate the performance of a building cluster with a shared PV system and a centralized heating system [41]. Munkhammar et al., analyzed the PV power self-consumption rates under different levels of EV penetration [142]. Another indicator closely related to the SC is self-sufficiency (SS) [142]. Boeckl and Kienberger used SS to evaluate PV-storage systems and tried to maximize the SS with the smallest possible system capacity, with the aim of maximizing the usage of resources [65].

Regarding economic performance assessment, cost of energy (COE) is also the simplest economic indicator of PV systems. Sabah et al., calculated the COE of 15 types of PV systems in 25 different locations inside a region in Oman and then determined the best PV system site and the best type of PV system for a village based on the calculated COE [61]. Net present value (NPV) evaluates the profitability of the investment [50]. O'Shaughnessy et al., analyzed the improvements in PV system NPV using a renewable energy optimization model [143]. Heine et al., used NPV as an indicator to search the optimal capacity of a battery in achieving the best economic performance [144]. Based on $\mathrm{NPV}$, it is also possible to calculate the internal rate of return (IRR), being a discount rate that makes the NPV of all cash flows equal to zero [145]. The Profitability Index (PI) also helps to assess the profitability of the investment and even rank the proposed layouts by quantifying the amount of value created per unit of investment [50]. Barone et al., adopted PI to assess the profitability of making profits for an investment. To compare electricity prices across different technologies, such as fossil fuel-based grid power, standalone PV systems, etc., the levelized cost of electricity (LCOE) is commonly applied. Kästel and Gilroy-Scott compared electricity prices for wind and PV technologies based on LCOE [139]. For a system including EVs, a separate energy storage system and renewable energy supply, total operation cost $\left(C_{\text {total }}\right)$ is a common parameter in the economic aspect. In view of the total operation cost, Sun et al., developed an operational cost minimization model for a residential energy system consisting of an EV, an energy storage system, a PV system and other residential loads [48]. Another commonly used index for economic analysis is the simple payback period (SPB). Barone et al., calculated SPB for a system renovation under different scenarios, including a vehicle to building system (V2B) and building to vehicle to building (V2B2) [50].

Regarding environmental performance assessment, for EVs with different electricity technologies, greenhouse gas (GHG) emission is the major concern. In the same way as a life cycle assessment, well-to-wheels analysis (WTW) is an environmental metric especially for EVs [43]. Querini et al., used WTW analysis to calculate the GHG emissions of EVs and the results showed that EVs with PV electricity always released less GHG than conventional thermal vehicles [43]. Another commonly used environmental footprint indicator is carbon intensity (CI). In a recent study, Miller et al., built a performance model to estimate PV power's CI under diverse scenarios and analyze the impacts of distinct influencing factors [140].

\section{Future Directions}

Advanced building coordinated controls with EV regulating should be considered: As reviewed in Section 3.4, the existing studies have developed a number of controls for both the electrical/thermal energy storage and EVs. These controls can be divided into individual controls (i.e., focusing on 
single-level performance) and coordinated controls (i.e., focusing on multiple-level performance). However, with the concern of complexity, the existing controls rarely integrate EV operating controls into whole-building energy system management. The flexible charging/discharging capability of EV batteries is not fully exploited, which restrains the cluster-level performance in renewable energy utilization. Future work is needed to develop more comprehensive and advanced controls, which can fully deploy both electrical/thermal energy storage and EVs.

Alternating current $(A C)$ power or direct current $(D C)$ power: In recent decades, modern solutions have raised a number of DC loads (e.g., pumps, compressors, servers, EVs, etc.), and most of the renewable-based distributed generation units directly produce DC output power. Considering the increased energy efficiency, the improved system reliability and the reduced complexity of DC microgrids, researchers have reconsidered the DC power grid for application, instead of using AC power. As introduced in Section 3.3, most of the existing energy sharing networks are based on DC power. However, not all of these redesigning procedures for the DC power grid have been accomplished yet. More research is needed to make such advanced systems a reality on a large scale. In addition to the technical development of DC microgrids and related controls, great efforts are also needed in legislation to promote the real implementation of an energy sharing DC microgrid, since the legislation on DC power microgrids and energy sharing among different buildings is still unclear in many countries.

Proper plans for energy sharing building clusters: The benefits brought by renewable energy sharing among different buildings, e.g., increased renewable energy self-utilization and reduced energy storage capacity required, are greatly affected by the type of buildings in the cluster [11]. For instance, there can be more renewable energy sharing between a residential building and an office building, compared with that shared between two residential buildings. Therefore, building clusters, in which energy sharing is enabled, should be well planned to maximize the benefits brought by renewable energy sharing. Apart from the energy characteristics, the geographical locations of the buildings should also be considered to avoid large energy loss due to long-distance power transmission. Future work is needed to develop such building cluster plan methods.

Proper pricing strategies for promoting solar mobility: The electricity pricing strategy has large impacts on renewable energy flow, as well as solar mobility [146]. There are two sets of electricity prices involved in this context: the prices of electricity purchased from or sold to the power grid, and the prices of electricity purchased/sold within the energy sharing building neighborhood. The latter price is proposed due to the developing trends of building clusters and energy sharing concepts. A proper pricing strategy should be able to provide incentives for households when they share their surplus solar power generations [22]. Future work is needed to develop such a pricing strategy.

Communication protocols: The imbalance between power demand and supply may cause line congestion, overload, reverse power flow, voltage-VAR (i.e., volt-ampere reactive) deviations and excessive phase imbalances. To mitigate such conditions and guarantee system integrity within its technical limits, clear monitoring structure and management protocols need to be defined and implemented. In fact, as illustrated in Figure 6, as EV and DER can belong to different domains and subdomains (i.e., DER, consumption, industrial, commercial and residential), the domain affiliation implies different energy management strategies and communications support. To ensure reliable and safe information exchanges between the facilities and demands in different domains and fields, future work is also needed to develop proper communication protocols.

\section{Conclusions}

This paper conducted a systematic review of the existing studies related to the solar energy, building, EVs, energy storage system and the energy sharing concept for promoting renewable energy utilization and solar mobility. Up-to-date studies about solar-to-building, vehicle and storage (S2BVS) in relation to essential components, including building-side modeling, EV modeling, grid modeling and advanced controls, have been reviewed and summarized. Such a solar mobility model can fully exploit 
the potential of PV systems, energy storage systems, EVs, and energy sharing networks, as well as advanced controls, to achieve an optimized performance at the microgrid level (e.g., increased renewable self-utilization and autonomy). Next, the platforms that can be used in the S2BVS modeling framework were reviewed from the aspects of demand/supply modeling, powerline/power grid modeling, and control implementation. The related performance indicators in the S2BVS modeling framework were reviewed from the perspectives of energy, economy and environment. Lastly, the remaining research gap in S2BVS techniques and improving solar mobility were identified. Future work is needed to develop advanced building coordinated controls with EV regulation considered, to make a selection between the AC power or DC power microgrid, to develop a proper method for energy sharing building clusters, to develop a proper pricing strategy for promoting solar mobility and to develop proper communication protocols. This study can help improve the existing solar mobility concept, so as to enhance renewable energy utilization efficiency corresponding to a future scenario with increased PV capacity, EV numbers and storage capacities.

Author Contributions: Conceptualization, X.Z. and P.H.; writing-original draft preparation, P.H., X.Z., B.C., P.K.S., Y.W.; writing-review and editing, D.Y., X.C.; supervision, X.Z.; project administration, X.Z.; funding acquisition, X.Z. All authors have read and agreed to the published version of the manuscript.

Funding: This research was funded by the EU Horizon 2020 EnergyMatching project (grant number 768766), the UBMEM project of the Swedish Energy Agency (grant number 46068), and the J. Gust. Richert foundation in Sweden (grant number: 2020-00586).

Conflicts of Interest: The authors declare no conflict of interest.

\section{References}

1. Cao, X.; Dai, X.; Liu, J. Building energy-consumption status worldwide and the state-of-the-art technologies for zero-energy buildings during the past decade. Energy Build. 2016, 128, 198-213. [CrossRef]

2. U.S. Energy Information Administration (EIA). International Energy Outlook 2016: Transportation Sector Energy Consumption; U.S. Energy Information Administration (EIA): Washington, DC, USA, 2016; pp. 127-137.

3. Merrill, L.; Bridle, R.; Gerasimchuk, I.; Touchette, Y.; Gagnon-Lebrun, F.; Lontoh, L.; Sharma, S.; Gass, P.; Sanchez, L.; Klimscheffskij, M.; et al. Making the Switch: From Fossil Fuel Subsidies to Sustainable Energy: Nordic Council of Ministers; Nordisk Ministerråd: Copenhagen, Denmark, 2017.

4. European Parliament. Energy: New Target of 32\% From Renewables by 2030 Agreed by MEPs and Ministers; European Parliament: Brussels, Belgium, 2018.

5. U.S. Energy Information Administration (EIA). Updated Renewable Portfolio Standards Will Lead to More Renewable Electricity Generation. Available online: https://www.eia.gov/todayinenergy/detail.php?id=38492 (accessed on 18 October 2019).

6. Bloomberg News Editors. China Sets Renewable Energy Target of 35\% by 2030 Amid Concerns About New Coal-Plant Construction. 2018. Available online: https://www.renewableenergyworld.com/2018/09/26/chinasets-new-renewables-target-of-35-percent-by-2030/\#gref (accessed on 22 October 2019).

7. SolarPower Europe. Global Market Outlook for Solar Power/2018-2022; SolarPower Europe: Brussels, Belgium, 2018.

8. Xylia, M.; Silveira, S. On the road to fossil-free public transport: The case of Swedish bus fleets. Energy Policy 2017, 100, 397-412. [CrossRef]

9. U.S. International Energy Agency (IEA). United States-Policies and Legislation. Available online: http: //www.ieahev.org/by-country/united-states-policy-and-legislation/ (accessed on 25 October 2019).

10. Hong Kong Environmental Protection Department (EPD). Promotion of Electric Vehicles in Hong Kong. Available online: https://www.epd.gov.hk/epd/english/environmentinhk/air/prob_solutions/promotion_ev. html (accessed on 20 March 2019).

11. Huang, P.; Sun, Y. A clustering based grouping method of nearly zero energy buildings for performance improvements. Appl. Energy 2019, 235, 43-55. [CrossRef]

12. Lokesh, B.T.; Hui Min, J.T. A Framework for Electric Vehicle (EV) Charging in Singapore. Energy Procedia 2017, 143, 15-20. [CrossRef] 
13. Land Transportation Authority. Joint News Release by the Land Transport Authority (LTA) \& EDB—Electric Vehicles (EVs) in Every HDB Town by 2020. Available online: https://www.lta.gov.sg/apps/news/page.aspx? c=2\&id=19d58dsztx5r0rw2621vtmjfe35nxru5c7ggg1yi3172m8ijqp (accessed on 18 October 2019).

14. Merten, J.; Guillou, H.; Ha, L.; Quenard, M.; Wiss, O.; Barruel, F. Solar Mobility: Two Years of Practical Experience Charging Ten Cars with Solar Energy. In Proceedings of the 5th International Conference on Integration of Renewable and Distributed Energy Resources, Berlin, Germany, 4-6 December 2012.

15. Cooper, A.I.; Schefter, K.E. Electric Vehicle Sales Forecast and the Charging Infrastructure Required through 203; Edison Electric Institute: Washington, DC, USA, 2018.

16. II G. LOI n 2010-788 du 12 Juillet 2010 Portant Engagement National Pour L'Environnement. 2010. Available online: https://www.legifrance.gouv.fr/affichTexte.do?cidTexte=JORFTEXT000022470434 (accessed on 21 October 2019).

17. IRENA. Electricity Storage and Renewables: Costs and Markets to 2030; International Renewable Energy Agency: Abu Dhabi, UAE, 2017.

18. ASHRAE. ASHRAE Handbook-HVAC Applications; Refrigerating and Air-Conditioning Engineers, American Society of Heating: Atlanta, GA, USA, 2011.

19. EMSD. Hong Kong Energy End-Use Data. Available online: https://www.emsd.gov.hk/en/energy_efficiency/ energy_end_use_data_and_consumption_indicators/hong_kong_energy_end_use_data (accessed on 20 October 2019).

20. Huang, P.; Huang, G.; Sun, Y. Uncertainty-based life-cycle analysis of near-zero energy buildings for performance improvements. Appl. Energy 2018, 213, 486-498. [CrossRef]

21. Tongsopit, S.; Junlakarn, S.; Wibulpolprasert, W.; Chaianong, A.; Kokchang, P.; Hoang, N.V.; Julakarn, S.; Wibulpholprasert, W. The economics of solar PV self-consumption in Thailand. Renew. Energy 2019, 138, 395-408. [CrossRef]

22. Lovati, M.; Zhang, X.; Huang, P.; Olsmats, C.; Maturi, L. Optimal simulation of three peer to peer (P2P) business models for individual PV prosumers in a local electricity market using agent-based modelling. Buildings 2020, 10, 138. [CrossRef]

23. Huang, P.; Huang, G.; Sun, Y. A robust design of nearly zero energy building systems considering performance degradation and maintenance. Energy 2018, 163, 905-919. [CrossRef]

24. Huang, P.; Sun, Y. A collaborative demand control of nearly zero energy buildings in response to dynamic pricing for performance improvements at cluster level. Energy 2019, 174, 911-921. [CrossRef]

25. The European Parliament and the Council of the European Union. Directive 2010/31/EU of the European Parliament and of the Council of 19 May 2010 on the Energy Performance of Buildings (Recast). Off. J. Eur. Union 2010, 18, 13-35.

26. Zebra2020. Nearly Zero-Energy Building Strategy 2020. Available online: http://zebra2020.eu (accessed on 20 October 2019).

27. Crawley, D.; Pless, S.; Torcellini, P. Getting to net zero. ASHRAE J. 2009, 51, 18-25.

28. IPEEC Taskgroup. Zero Energy Building Definitions and Policy Activity: An International Review; IPEEC Building Energy Efficiency Taskgroup: Golden, CO, USA, 2018; p. 40.

29. Tronchin, L.; Manfren, M.; Nastasi, B. Energy efficiency, demand side management and energy storage technologies-A critical analysis of possible paths of integration in the built environment. Renew. Sustain. Energy Rev. 2018, 95, 341-353. [CrossRef]

30. Vu, T.; Barruel, F.; Merten, J. Design of a Management and Simulation's Tool for Solar Car Park. In Proceedings of the 23rd European Photovoltaic Solar Energy Conference and Exhibition, Valencia, Spain, 1-5 September 2008; pp. 3443-3446.

31. Taverdet-Popiolek, N.; Thais, F. Multi-criteria analysis of innovation policies in favour of solar mobility in France by 2030. Energy Policy 2016, 97, 202-219. [CrossRef]

32. Birnie, D.P. Solar-to-vehicle (S2V) systems for powering commuters of the future. J. Power Sources 2009, 186, 539-542. [CrossRef]

33. Kempton, W.; Letendre, S.E. Electric vehicles as a new power source for electric utilities. Transp. Res. Part D Transp. Environ. 1997, 2, 157-175. [CrossRef]

34. Schwan, D.-I.T.; Unger, R.; Bäker, B. Modelling and Optimization of Renewable Energy Supply for Electrified Vehicle Fleet. In Proceedings of the 8th Conference on Sustainable Development of Energy, Water and Environment Systems, Dubrovnik, Croatia, 22-27 September 2013. 
35. Zhang, Q.; Tezuka, T.; Ishihara, K.N.; McLellan, B.; Keiichi, I. Integration of PV power into future low-carbon smart electricity systems with EV and HP in Kansai area, Japan. Renew. Energy 2012, 44, 99-108. [CrossRef]

36. Nunes, P.; Farias, T.L.; Brito, M.C. Day charging electric vehicles with excess solar electricity for a sustainable energy system. Energy 2015, 80, 263-274. [CrossRef]

37. Codani, P.; Le Portz, P.-L.; Claverie, P.; Petit, M.; Perez, Y. Coupling local renewable energy production with electric vehicle charging: A survey of the French case. Int. J. Automot. Technol. Manag. 2016, 16, 55. [CrossRef]

38. Mesarić, P.; Krajcar, S. Home demand side management integrated with electric vehicles and renewable energy sources. Energy Build. 2015, 108, 1-9. [CrossRef]

39. Taşcıkaraoğlu, A. Economic and operational benefits of energy storage sharing for a neighborhood of prosumers in a dynamic pricing environment. Sustain. Cities Soc. 2018, 38, 219-229. [CrossRef]

40. Zhang, B.; Li, Q.; Wang, L.; Feng, W. Robust optimization for energy transactions in multi-microgrids under uncertainty. Appl. Energy 2018, 217, 346-360. [CrossRef]

41. Huang, P.; Lovati, M.; Zhang, X.; Bales, C.; Hallbeck, S.; Becker, A.; Bergqvist, H.; Hedberg, J.; Maturi, L. Transforming a residential building cluster into electricity prosumers in Sweden: Optimal design of a coupled PV-heat pump-thermal storage-electric vehicle system. Appl. Energy 2019, 255, 113864. [CrossRef]

42. Berthold, F.; Blunier, B.; Bouquain, D.; Williamson, S.; Miraoui, A. PHEV Control Strategy Including Vehicle to Home (V2H) and Home to Vehicle (H2V) Functionalities. In Proceedings of the 2011 IEEE Vehicle Power and Propulsion Conference, Chicago, IL, USA, 6-9 September 2011; pp. 1-6.

43. Querini, F.; Dagostino, S.; Morel, S.; Rousseaux, P. Greenhouse gas emissions of electric vehicles associated with wind and photovoltaic electricity. Energy Procedia 2012, 20, 391-401. [CrossRef]

44. Dallinger, D.; Gerda, S.; Wietschel, M. Integration of intermittent renewable power supply using grid-connected vehicles-A 2030 case study for California and Germany. Appl. Energy 2013, 104, 666-682. [CrossRef]

45. Su, W.; Wang, J.; Roh, J. Stochastic energy scheduling in microgrids with intermittent renewable energy resources. IEEE Trans. Smart Grid 2013, 5, 1876-1883. [CrossRef]

46. Chaouachi, A.; Bompard, E.; Fulli, G.; Masera, M.; De Gennaro, M.; Paffumi, E. Assessment framework for EV and PV synergies in emerging distribution systems. Renew. Sustain. Energy Rev. 2016, 55, 719-728. [CrossRef]

47. Islam, S.; Mithulananthan, N. PV based EV charging at universities using supplied historical PV output ramp. Renew. Energy 2018, 118, 306-327. [CrossRef]

48. Sun, Y.; Yue, H.; Zhang, J.; Booth, C. Minimization of residential energy cost considering energy storage system and EV with driving usage probabilities. IEEE Trans. Sustain. Energy 2019, 10, 1752-1763. [CrossRef]

49. Huang, Z.; Xie, Z.; Zhang, C.; Chan, S.H.; Milewski, J.; Xie, Y.; Yang, Y.; Hu, X. Modeling and multi-objective optimization of a stand-alone PV-hydrogen-retired EV battery hybrid energy system. Energy Convers. Manag. 2019, 181, 80-92. [CrossRef]

50. Barone, G.; Buonomano, A.; Calise, F.; Forzano, C.; Palombo, A. Building to vehicle to building concept toward a novel zero energy paradigm: Modelling and case studies. Renew. Sustain. Energy Rev. 2019, 101, 625-648. [CrossRef]

51. Noussan, M.; Neirotti, F. Cross-country comparison of hourly electricity mixes for ev charging profiles. Energies 2020, 13, 2527. [CrossRef]

52. Meteotest. Meteonorm Software. Available online: https://meteonorm.com/en (accessed on 5 December 2019).

53. Global Solar Atlas. Available online: https://globalsolaratlas.info/map (accessed on 20 December 2019).

54. Zhang, J.; Zhao, L.; Deng, S.; Xu, W.; Zhang, Y. A critical review of the models used to estimate solar radiation. Renew. Sustain. Energy Rev. 2017, 70, 314-329. [CrossRef]

55. Besharat, F.; Dehghan, A.A.; Faghih, A.R. Empirical models for estimating global solar radiation: A review and case study. Renew. Sustain. Energy Rev. 2013, 21, 798-821. [CrossRef]

56. Sola, A.; Corchero, C.; Salom, J.; Sanmarti, M. Simulation tools to build urban-scale energy models: A review. Energies 2018, 11, 3269. [CrossRef]

57. Quan, S.J.; Li, Q.; Augenbroe, G.; Brown, J.; Yang, P.P.-J. A GIS-based energy balance modeling system for urban solar buildings. Energy Procedia 2015, 75, 2946-2952. [CrossRef] 
58. Bergamasco, L.; Asinari, P. Scalable methodology for the photovoltaic solar energy potential assessment based on available roof surface area: Application to Piedmont region (Italy). Sol. Energy 2011, 85, 1041-1055. [CrossRef]

59. Lingfors, D. Solar Variability Assessment in the Built Environment: Model Development and Application to Grid Integration. Ph.D. Thesis, Acta Universitatis Upsaliensis, Uppsala, Sweden, 2017.

60. Jochem, A.; Höfle, B.; Hollaus, M.; Rutzinger, M. Object detection in airborne LIDAR data for improved solar radiation modeling in urban areas. Int. Arch. Photogramm. Remote Sens. Spat. Inf. Sci. Paris 2009, 38, W8.

61. Abdul-Wahab, S.A.; Charabi, Y.; Al-Mahruqi, A.M.; Osman, I.; Osman, S. Selection of the best solar photovoltaic (PV) for Oman. Sol. Energy 2019, 188, 1156-1168. [CrossRef]

62. Ning, G.; Junnan, L.; Yansong, D.; Zhifeng, Q.; Qingshan, J.; Weihua, G.; Geert, D. BIM-based PV system optimization and deployment. Energy Build. 2017, 150, 13-22. [CrossRef]

63. Ullah, A.; Imran, H.; Maqsood, Z.; Butt, N.Z. Investigation of optimal tilt angles and effects of soiling on PV energy production in Pakistan. Renew. Energy 2019, 139, 830-843. [CrossRef]

64. Shirazi, A.M.; Zomorodian, Z.S.; Tahsildoost, M. Techno-economic BIPV evaluation method in urban areas. Renew. Energy 2019, 143, 1235-1246. [CrossRef]

65. Böckl, B.; Kienberger, T. Sizing of PV storage systems for different household types. J. Energy Storage 2019, 24, 100763. [CrossRef]

66. Fonseca, J.A.; Schlueter, A. Integrated model for characterization of spatiotemporal building energy consumption patterns in neighborhoods and city districts. Appl. Energy 2015, 142, 247-265. [CrossRef]

67. Tardioli, G.; Kerrigan, R.; Oates, M.; Donnell, J.O.; Finn, D. A Data-Driven Modelling Approach for Large Scale Demand Profiling of Residential Buildings. In Proceedings of the 15th IBPSA Conference, San Francisco, CA, USA, 7-9 August 2017.

68. Palacios-Garcia, E.J.; Moreno-Muñoz, A.; Santiago, I.; Flores-Arias, J.; Bellido, F.; Moreno-Garcia, I.M. A stochastic modelling and simulation approach to heating and cooling electricity consumption in the residential sector. Energy 2018, 144, 1080-1091. [CrossRef]

69. Palacios-Garcia, E.J.; Chen, A.; Santiago, I.; Bellido-Outeiriño, F.J.; Flores-Arias, J.M.; Moreno-Munoz, A. Stochastic model for lighting's electricity consumption in the residential sector. Impact of energy saving actions. Energy Build. 2015, 89, 245-259. [CrossRef]

70. Widén, J.; Wäckelgård, E. A high-resolution stochastic model of domestic activity patterns and electricity demand. Appl. Energy 2010, 87, 1880-1892. [CrossRef]

71. Fumo, N.; Biswas, M.R. Regression analysis for prediction of residential energy consumption. Renew. Sustain. Energy Rev. 2015, 47, 332-343. [CrossRef]

72. Ahmad, T.; Chen, H.; Guo, Y.; Wang, J. A comprehensive overview on the data driven and large scale based approaches for forecasting of building energy demand: A review. Energy Build. 2018, 165, 301-320. [CrossRef]

73. Hsieh, S.; Omu, A.; Orehounig, K. Comparison of solar thermal systems with storage: From building to neighbourhood scale. Energy Build. 2017, 152, 359-372. [CrossRef]

74. Rodriguez, L.R.; Ramos, J.S.; Delgado, M.G.; Félix, J.L.M.; Domínguez, S. Álvarez Mitigating energy poverty: Potential contributions of combining PV and building thermal mass storage in low-income households. Energy Convers. Manag. 2018, 173, 65-80. [CrossRef]

75. Roberts, M.B.; Bruce, A.; MacGill, I. Impact of shared battery energy storage systems on photovoltaic self-consumption and electricity bills in apartment buildings. Appl. Energy 2019, 245, 78-95. [CrossRef]

76. Koskela, J.; Rautiainen, A.; Järventausta, P. Using electrical energy storage in residential buildings—Sizing of battery and photovoltaic panels based on electricity cost optimization. Appl. Energy 2019, 239, 1175-1189. [CrossRef]

77. Parra, D.; Norman, S.A.; Walker, G.S.; Gillott, M. Optimum community energy storage system for demand load shifting. Appl. Energy 2016, 174, 130-143. [CrossRef]

78. Parra, D.; Gillott, M.; Norman, S.A.; Walker, G.S. Optimum community energy storage system for PV energy time-shift. Appl. Energy 2015, 137, 576-587. [CrossRef]

79. Sardi, J.; Mithulananthan, N.; Hung, D.Q. Strategic allocation of community energy storage in a residential system with rooftop PV units. Appl. Energy 2017, 206, 159-171. [CrossRef] 
80. Ali, M.U.; Zafar, A.; Nengroo, S.H.; Hussain, S.; Alvi, M.J.; Kim, H.-J. Towards a smarter battery management system for electric vehicle applications: A critical review of lithium-ion battery state of charge estimation. Energies 2019, 12, 446. [CrossRef]

81. Universiy, B. Batteries as Power Source. BU-1003: Electric Vehicle (EV). 2019. Available online: https: //batteryuniversity.com/learn/article/electric_vehicle_ev (accessed on 10 October 2019).

82. Hall, J.; Lin, T.; Brown, G.; Biensan, P.; Bonhomme, F. Decay Processes and Life Predictions for Lithium Ion Satellite Cells. In Proceedings of the 4th International Energy Conversion Engineering Conference and Exhibit (IECEC), San Diego, CA, USA, 26-29 June 2006.

83. Geth, F.; Willekens, K.; Clement, K.; Driesen, J.; De Breucker, S. Impact-analysis of the charging of plug-in hybrid vehicles on the production park in Belgium. In Proceedings of the Melecon 2010-2010 15th IEEE Mediterranean Electrotechnical Conference, Valletta, Malta, 26-28 April 2010; pp. 425-430.

84. Lee, T.-K.; Adornato, B.; Filipi, Z. Synthesis of real-world driving cycles and their use for estimating PHEV energy consumption and charging opportunities: Case study for midwest/U.S. IEEE Trans. Veh. Technol. 2011, 60, 4153-4163. [CrossRef]

85. Fischer, D.; Harbrecht, A.; Surmann, A.; McKenna, R. Electric vehicles' impacts on residential electric local profiles-A stochastic modelling approach considering socio-economic, behavioural and spatial factors. Appl. Energy 2019, 233-234, 644-658. [CrossRef]

86. Lojowska, A.; Kurowicka, D.; Papaefthymiou, G.; Van Der Sluis, L. From transportation patterns to power demand: Stochastic modeling of uncontrolled domestic charging of electric vehicles. In Proceedings of the 2008 IEEE Power and Energy Society General Meeting-Conversion and Delivery of Electrical Energy in the 21st Century, Pittsburgh, PA, USA, 20-24 July 2011; pp. 1-7.

87. Shahidinejad, S.; Filizadeh, S.; Bibeau, E. Profile of charging load on the grid due to plug-in vehicles. IEEE Trans. Smart Grid 2011, 3, 135-141. [CrossRef]

88. Soares, F.; Lopes, J.A.; Almeida, P.; Moreira, C.; Seca, L. A Stochastic Model to Simulate Electric Vehicles Motion and Quantify the Energy Required from The Grid. In Proceedings of the 17th Power Systems Computation Conference, Stockholm, Sweden, 22-26 August 2011.

89. Grahn, P.; Alvehag, K.; Munkhammar, J.; Widén, J.; Soder, L. PHEV Home-Charging Model Based on Residential Activity Patterns. IEEE Trans. Power Syst. 2013, 28, 2507-2515. [CrossRef]

90. Munkhammar, J.; Widén, J.; Rydén, J. On a probability distribution model combining household power consumption, electric vehicle home-charging and photovoltaic power production. Appl. Energy 2015, 142, 135-143. [CrossRef]

91. Darabi, Z.; Ferdowsi, M. Extracting probability distribution functions applicable for PHEVs charging load profile. In Proceedings of the IEEE PES Transmission and Distribution Conference and Exposition (PES T\&D 2012), Orlando, FL, USA, 7-10 May 2012. [CrossRef]

92. Verzijlbergh, R.A.; Lukszo, Z.; Veldman, E.; Slootweg, J.G.; Ilic, M. Deriving Electric Vehicle Charge Profiles from Driving Statistics. In Proceedings of the 2011 IEEE Power and Energy Society General Meeting, Detroit, MI, USA, 24-28 July 2011; pp. 1-6. [CrossRef]

93. Fischer, D.; Scherer, J.; Flunk, A.; Kreifels, N.; Byskov-Lindberg, K.; Wille-Haussmann, B. Impact of HP, CHP, PV and EVs on households' electric load profiles. In Proceedings of the 2015 IEEE Eindhoven PowerTech, Eindhoven, The Netherlands, 29 June-2 July 2015.

94. Islam, S.; Mithulananthan, N.; Hung, D.Q.; Nadarajah, M.; Duong, Q.H. A Day-Ahead Forecasting Model for Probabilistic EV Charging Loads at Business Premises. IEEE Trans. Sustain. Energy 2018, 9, 741-753. [CrossRef]

95. Islam, S.; Mithulananthan, N.; Hung, D.Q. Coordinated EV charging for correlated EV and grid loads and PV output using a novel, correlated, probabilistic model. Int. J. Electr. Power Energy Syst. 2019, 104, 335-348. [CrossRef]

96. Luo, L.; Gu, W.; Wu, Z.; Zhou, S. Joint planning of distributed generation and electric vehicle charging stations considering real-time charging navigation. Appl. Energy 2019, 242, 1274-1284. [CrossRef]

97. Morrissey, P.; Weldon, P.; O'Mahony, M. Future standard and fast charging infrastructure planning: An analysis of electric vehicle charging behaviour. Energy Policy 2016, 89, 257-270. [CrossRef]

98. Greer, C.; Wollman, D.A.; Prochaska, D.E.; Boynton, P.A.; Mazer, J.A.; Nguyen, C.; Fitzpatrick, G.J.; Nelson, T.L.; Koepke, G.H.; Hefner, A.R.; et al. NIST Framework and Roadmap for Smart Grid Interoperability Standards, Release 3.0; Special Publication (NIST SP): Gaithersburg, MD, USA, 2014. 
99. Aymen, C.; Catalin-Felix, C.; Gianluca, F. Framework for Electric Vehicles and Photovoltaic Synergies; Publications Office of the European Union: Brussels, Belgium, 2016.

100. IEC 61968-11. Application Integration at Electric Utilities-System Interfaces for Distribution Management-Part 11: Common Information Model (CIM) Extensions for Distribution Solution; German Institute for Standardisation: Berlin, Germany, 2013.

101. IEC 61970-301:2011. Energy Management System Application Program Interface (EMS-API)_Part 301: Common Information Model (CIM) Base; German Institute for Standardisation: Berlin, Germany, 2011.

102. Bruinenberg, J.; Colton, L.; Darmois, E.; Dorn, J.; Doyle, J.; Elloumi, O.; Englert, H.; Forbes, R.; Heiles, J.; Hermans, P.; et al. CEN-CENELEC-ETSI: Smart Grid Coordination Group-Smart Grid Reference Architecture Report 2.0; CEN-CENELEC-ETSI: Brussels, Belgium, 2012.

103. Huang, P.; Wu, H.; Huang, G.; Sun, Y. A top-down control method of nZEBs for performance optimization at nZEB-cluster-level. Energy 2018, 159, 891-904. [CrossRef]

104. Odonkor, P.; Lewis, K.E. Adaptive Operation Decisions in Net Zero Building Clusters. In Proceedings of the ASME 2015 International Design Engineering Technical Conferences and Computers and Information in Engineering Conference, Boston, MA, USA, 2-5 August 2015.

105. Chen, Y.-K.; Wu, Y.-C.; Song, C.-C.; Chen, Y.-S. Design and implementation of energy management system with fuzzy control for DC microgrid systems. IEEE Trans. Power Electron. 2012, 28, 1563-1570. [CrossRef]

106. Ayai, N.; Hisada, T.; Shibata, T.; Miyoshi, H.; Iwasaki, T.; Kitayama, K.-I. DC Micro grid system. Electr. Wire Cable Energy 2012, 75, 132-136.

107. Ferroamp. The EnergyHub System. Available online: https://static.ferroamp.com/files/brochure/en/ Ferroamp\%20Brochure\%20English\%202018.pdf (accessed on 10 May 2019).

108. Zhao, Y.; Lu, Y.; Yan, C.; Wang, S. MPC-based optimal scheduling of grid-connected low energy buildings with thermal energy storages. Energy Build. 2015, 86, 415-426. [CrossRef]

109. Lu, Y.; Wang, S.; Sun, Y.; Yan, C. Optimal scheduling of buildings with energy generation and thermal energy storage under dynamic electricity pricing using mixed-integer nonlinear programming. Appl. Energy 2015, 147, 49-58. [CrossRef]

110. Allison, J. Robust multi-objective control of hybrid renewable microgeneration systems with energy storage. Appl. Therm. Eng. 2017, 114, 1498-1506. [CrossRef]

111. Cai, J.; Zhang, H.; Jin, X. Aging-aware predictive control of PV-battery assets in buildings. Appl. Energy 2019, 236, 478-488. [CrossRef]

112. Wu, X.; Hu, X.; Teng, Y.; Qian, S.; Cheng, R. Optimal integration of a hybrid solar-battery power source into smart home nanogrid with plug-in electric vehicle. J. Power Sources 2017, 363, 277-283. [CrossRef]

113. Fan, C.; Huang, G.; Sun, Y. A collaborative control optimization of grid-connected net zero energy buildings for performance improvements at building group level. Energy 2018, 164, 536-549. [CrossRef]

114. Prasad, A.; Dusparic, I. Multi-agent Deep Reinforcement Learning for Zero Energy Communities. In Proceedings of the 2019 IEEE PES Innovative Smart Grid Technologies Europe (ISGT-Europe), Bucharest, Romania, 29 September-2 October 2019; pp. 1-5.

115. Ma, L.; Liu, N.; Wang, L.; Zhang, J.; Lei, J.; Zeng, Z.; Wang, C.; Cheng, M. Multi-party energy management for smart building cluster with PV systems using automatic demand response. Energy Build. 2016, 121, 11-21. [CrossRef]

116. Usman, M.; Knapen, L.; Yasar, A.-U.-H.; Vanrompay, Y.; Bellemans, T.; Janssens, D.; Wets, G. A coordinated Framework for Optimized Charging of EV Fleet in Smart Grid. Procedia Comput. Sci. 2016, 94, 332-339. [CrossRef]

117. Zhong, J.; He, L.; Li, C.; Cao, Y.; Wang, J.; Fang, B.; Zeng, L.; Xiao, G. Coordinated control for large-scale EV charging facilities and energy storage devices participating in frequency regulation. Appl. Energy 2014, 123, 253-262. [CrossRef]

118. Li, Y.; Li, L.; Peng, C.; Zou, J. An MPC based optimized control approach for EV-based voltage regulation in distribution grid. Electr. Power Syst. Res. 2019, 172, 152-160. [CrossRef]

119. Jia, H.; Li, X.; Mu, Y.; Xu, C.; Jiang, Y.; Yu, X.; Wu, J.; Dong, C. Coordinated control for EV aggregators and power plants in frequency regulation considering time-varying delays. Appl. Energy 2018, 210, 1363-1376. [CrossRef]

120. Kumar, P.; Pukale, R.; Kumabhar, N.; Patil, U. Optimal Design Configuration Using HOMER. Procedia Technol. 2016, 24, 499-504. [CrossRef] 
121. Li, C.; Zhou, D.; Wang, H.; Cheng, H.; Li, N. Feasibility assessment of a hybrid PV/diesel/battery power system for a housing estate in the severe cold zone-A case study of Harbin, China. Energy 2019, 185, 671-681. [CrossRef]

122. The University of Wisconsin. Using Fortran Compilers with TRNSYS. 2006. Available online: https: //sel.me.wisc.edu/trnsys/fortran/fortran.htm (accessed on 15 March 2020).

123. Bava, F.; Furbo, S. Development and validation of a detailed TRNSYS-Matlab model for large solar collector fields for district heating applications. Energy 2017, 135, 698-708. [CrossRef]

124. Jonas, D.; Felgner, F.; Frey, G.; Theis, D. A user-friendly simulation framework for the analysis of solar thermal and heat pump systems using TRNSYS. In Proceedings of the 8th International Renewable Energy Congress (IREC 2017), Amman, Jordan, 21-23 March 2017. [CrossRef]

125. Saleem, M.S.; Abas, N.; Kalair, A.R.; Rauf, S.; Haider, A.; Tahir, M.S.; Sagir, M. Design and optimization of hybrid solar-hydrogen generation system using TRNSYS. Int. J. Hydrog. Energy 2020, 45, 15814-15830. [CrossRef]

126. Antoniadis, C.N.; Martinopoulos, G. Optimization of a building integrated solar thermal system with seasonal storage using TRNSYS. Renew. Energy 2019, 137, 56-66. [CrossRef]

127. Uygun, U.; Akgul, C.M.; Dino, I.G.; Akinoglu, B.G. Approaching Net-zero energy building through utilization of building-integrated photovoltaics for three cities in turkey-preliminary calculations. In Proceedings of the International Conference on Photovoltaic Science and Technologies (PVCon), Ankara, Turkey, 4-6 July 2018; pp. 1-4.

128. Boyano, A.; Hernandez, P.; Wolf, O. Energy demands and potential savings in European office buildings: Case studies based on EnergyPlus simulations. Energy Build. 2013, 65, 19-28. [CrossRef]

129. Bingham, R.D.; Agelin-Chaab, M.; Rosen, M.A. Whole building optimization of a residential home with PV and battery storage in The Bahamas. Renew. Energy 2019, 132, 1088-1103. [CrossRef]

130. Ke, B.-R.; Ku, T.-T.; Ke, Y.-L.; Chuang, C.-Y.; Chen, H.-Z. Sizing the battery energy storage system on a university campus with prediction of load and photovoltaic generation. In Proceedings of the IEEE/IAS 51st Industrial \& Commercial Power Systems Technical Conference (I\&CPS), Calgary, AB, Canada, 5-8 May 2015; pp. 1-12.

131. Supponen, A.; Rautiainen, A.; Markkula, J.; Makinen, A.; Jarventausta, P.; Repo, S. Power quality in distribution networks with electric vehicle charging-A research methodology based on field tests and real data. In Proceedings of the 2016 Eleventh International Conference on Ecological Vehicles and Renewable Energies (EVER), Monte Carlo, Monaco, 6-8 April 2016; pp. 1-11.

132. Ahamioje, J.A.; Krishnaswami, H.; Chaudhari, S.; Kannan, P.K.; Dey, S.R. Interconnection Study of Distributed PV Systems by Interfacing Matlab with OpenDSS and GIS. In Proceedings of the IEEE 44th Photovoltaic Specialist Conference (PVSC); Institute of Electrical and Electronics Engineers (IEEE), Washington, DC, USA, 25-30 June 2017; pp. 2931-2935.

133. Papas, I.; Estibals, B.; Ecrepont, C.; Alonso, C. Energy Consumption Optimization through Dynamic Simulations for an Intelligent Energy Management of a BIPV Building. In Proceedings of the 7th International Conference on Renewable Energy Research and Applications (ICRERA), Paris, France, 14-17 October 2018; pp. 853-857.

134. Lei, S.; Wang, H.; Lian, G. The joint simulation of a stand-alone photovoltaic system based on PSIM and Matlab. In Proceedings of the 20th International Conference on Electrical Machines and Systems (ICEMS), Sydney, Australia, 11-14 August 2017; pp. 1-4.

135. Barros, M.; Casquilho, M. Linear Programming with CPLEX: An Illustrative Application over the Internet CPLEX in Fortran 90. In Proceedings of the 14th Iberian Conference on Information Systems and Technologies (CISTI), Coimbra, Portugal, 19-22 June 2019; pp. 1-6.

136. Zuo, X.; Zhu, C.; Huang, C.; Xiao, Y. Using AMPL/CPLEX to model and solve the electric vehicle routing problem (EVRP) with heterogeneous mixed fleet. In Proceedings of the 29th Chinese Control and Decision Conference (CCDC), Chongqing, China, 28-30 May 2017; pp. 4666-4670.

137. Zakaria, R.; Dib, M.; Moalic, L.; Caminada, A. Car relocation for carsharing service: Comparison of CPLEX and greedy search. In Proceedings of the 2014 IEEE Symposium on Computational Intelligence in Vehicles and Transportation Systems (CIVTS); Institute of Electrical and Electronics Engineers (IEEE), Orlando, FL, USA, 9-12 December 2014; pp. 51-58. 
138. Adewuyi, O.B.; Lotfy, M.E.; Akinloye, B.O.; Howlader, H.O.R.; Senjyu, T.; Narayanan, K. Security-constrained optimal utility-scale solar PV investment planning for weak grids: Short reviews and techno-economic analysis. Appl. Energy 2019, 245, 16-30. [CrossRef]

139. Kästel, P.; Gilroy-Scott, B. Economics of pooling small local electricity prosumers-LCOE \& self-consumption. Renew. Sustain. Energy Rev. 2015, 51, 718-729. [CrossRef]

140. Miller, I.; Gençer, E.; Vogelbaum, H.S.; Brown, P.R.; Torkamani, S.; O’Sullivan, F.M. Parametric modeling of life cycle greenhouse gas emissions from photovoltaic power. Appl. Energy 2019, 238, 760-774. [CrossRef]

141. Luthander, R.; Widén, J.; Nilsson, D.; Palm, J. Photovoltaic self-consumption in buildings: A review. Appl. Energy 2015, 142, 80-94. [CrossRef]

142. Munkhammar, J.; Grahn, P.; Widén, J. Quantifying self-consumption of on-site photovoltaic power generation in households with electric vehicle home charging. Sol. Energy 2013, 97, 208-216. [CrossRef]

143. O'Shaughnessy, E.; Cutler, D.; Ardani, K.; Margolis, R. Solar plus: Optimization of distributed solar PV through battery storage and dispatchable load in residential buildings. Appl. Energy 2018, 213, 11-21. [CrossRef]

144. Heine, K.; Thatte, A.; CesarTabares-Velasco, P. A simulation approach to sizing batteries for integration with net-zero energy residential buildings. Renew. Energy 2019, 139, 176-185. [CrossRef]

145. Murphy, A.R.; Fung, A.S. Techno-economic study of an energy sharing network comprised of a data centre and multi-unit residential buildings for cold climate. Energy Build. 2019, 186, 261-275. [CrossRef]

146. Huang, P.; Xu, T.; Sun, Y. A genetic algorithm based dynamic pricing for improving bi-directional interactions with reduced power imbalance. Energy Build. 2019, 199, 275-286. [CrossRef]

(C) 2020 by the authors. Licensee MDPI, Basel, Switzerland. This article is an open access article distributed under the terms and conditions of the Creative Commons Attribution (CC BY) license (http://creativecommons.org/licenses/by/4.0/). 